\title{
Systems biology of cisplatin resistance: past, present and future
}

\author{
L Galluzzi ${ }^{*}, 1,2,3,16$, I Vitale $4^{4,5}$, J Michels ${ }^{1,3,6}$, C Brenner ${ }^{7,8}$, G Szabadkai ${ }^{9,10}$, A Harel-Bellan ${ }^{11,12,13}$, M Castedo ${ }^{1,3,6}$ \\ and G Kroemer ${ }^{\star}, 2,3,6,14,15,16$
}

The platinum derivative cis-diamminedichloroplatinum(II), best known as cisplatin, is currently employed for the clinical management of patients affected by testicular, ovarian, head and neck, colorectal, bladder and lung cancers. For a long time, the antineoplastic effects of cisplatin have been fully ascribed to its ability to generate unrepairable DNA lesions, hence inducing either a permanent proliferative arrest known as cellular senescence or the mitochondrial pathway of apoptosis. Accumulating evidence now suggests that the cytostatic and cytotoxic activity of cisplatin involves both a nuclear and a cytoplasmic component. Despite the unresolved issues regarding its mechanism of action, the administration of cisplatin is generally associated with high rates of clinical responses. However, in the vast majority of cases, malignant cells exposed to cisplatin activate a multipronged adaptive response that renders them less susceptible to the antiproliferative and cytotoxic effects of the drug, and eventually resume proliferation. Thus, a large fraction of cisplatin-treated patients is destined to experience therapeutic failure and tumor recurrence. Throughout the last four decades great efforts have been devoted to the characterization of the molecular mechanisms whereby neoplastic cells progressively lose their sensitivity to cisplatin. The advent of high-content and high-throughput screening technologies has accelerated the discovery of cell-intrinsic and cell-extrinsic pathways that may be targeted to prevent or reverse cisplatin resistance in cancer patients. Still, the multifactorial and redundant nature of this phenomenon poses a significant barrier against the identification of effective chemosensitization strategies. Here, we discuss recent systems biology studies aimed at deconvoluting the complex circuitries that underpin cisplatin resistance, and how their findings might drive the development of rational approaches to tackle this clinically relevant problem.

Cell Death and Disease (2014) 5, e1257; doi:10.1038/cddis.2013.428; published online 29 May 2014

Subject Category: Cancer

\footnotetext{
${ }^{1}$ Gustave Roussy, Villejuif, France; ${ }^{2}$ Université Paris Descartes/Paris V, Sorbonne Paris Cité, Paris, France; ${ }^{3}$ Equipe 11 labellisée par la Ligue Nationale contre le Cancer, Centre de Recherche des Cordeliers, Paris, France; ${ }^{4}$ Regina Elena National Cancer Institute, Rome, Italy; ${ }^{5}$ National Institute of Health, Rome, Italy; ${ }^{6}$ INSERM, U848, Villejuif, France; ${ }^{7}$ INSERM, UMRS 769; LabEx LERMIT, Châtenay Malabry, France; ${ }^{8}$ Faculté de Pharmacie, Université de Paris Sud/Paris XI, Châtenay Malabry, France; ${ }^{9}$ Department of Cell and Developmental Biology, Consortium for Mitochondrial Research, University College London, London, UK; ${ }^{10}$ Department of Biomedical Sciences, Università Degli Studi di Padova, Padova, Italy; ${ }^{11}$ Laboratoire Epigenetique et Cancer, Université de Paris Sud/Paris XI, Gif-Sur-Yvette, France; ${ }^{12} \mathrm{CNRS}$, FRE3377, Gif-Sur-Yvette, France; ${ }^{13}$ Commissariat à l'Energie Atomique (CEA), Saclay, France; ${ }^{14}$ Pôle de Biologie, Hôpital Européen Georges Pompidou, AP-HP, Paris, France and ${ }^{15}$ Metabolomics and Cell Biology Platforms, Gustave Roussy, Villejuif, France

*Corresponding authors: L Galluzzi, Université Paris Descartes/Paris V, INSERM, U848, Gustave Roussy, PR1, 39, rue Camille Desmoulins, Villejuif F-94805, France. Tel: +33 14211 4516; Fax: 3314211 6665; E-mail: deadoc@vodafone.it

or G Kroemer, INSERM, U848, Gustave Roussy, PR1, 39, rue Camille Desmoulins, Villejuif F-94805, France. Tel: +33 14211 6046; Fax: +33 14211 6047; E-mail: kroemer@orange.fr

${ }^{16}$ Share senior co-authorship.

Keywords: BCL-2; carboplatin; CTR1; DNA damage response; oxaliplatin; p53

Abbreviations: 5-FU, 5-fluorouracil; ABCC2, ATP-binding cassette, subfamily C (CFTR/MRP), member 2; AKT1, v-akt murine thymoma viral oncogene homolog 1; ATP7B, ATPase, $\mathrm{Cu}^{2+}$ transporting, $\beta$ polypeptide; BMP4, bone morphogenetic protein 4; BRCA1, breast cancer 1, early onset; BRCA2, breast cancer 2, early onset; CDDP, cis-diamminedichloroplatinum(II); CDK2, cyclin-dependent kinase 2; CTR1, copper transporter 1; DAPK3, death-associated protein kinase 3; DFS, disease-free survival; DSB, double-strand break; DYRK1B, dual-specificity Y-phosphorylation regulated kinase 1B; EGFR, epidermal growth factor receptor; EMT, epithelial-tomesenchymal transition; ER, endoplasmic reticulum; ERCC1, excision repair cross-complementing rodent repair deficiency, complementation group 1; FA, Fanconi anemia; FDA, Food and Drug Administration; FGFR2, fibroblast growth factor receptor 2; GSH, reduced glutathione; GST, glutathione S-transferase; HCC, hepatocellular carcinoma; HNSCC, head and neck squamous cell carcinoma; HR, homologous recombination; HSP, heat-shock protein; HTS, high-throughput screening; IL-7, interleukin-7; LCL, lymphoblastoid cell line; LIPC, lipase, hepatic; MAPK, mitogen-activated protein kinase; MAP3K1, mitogen-activated protein kinase kinase kinase 1; METTL6, methyltransferase like 6; MLH1, mutL homolog 1; MMR, mismatch repair; MOMP, mitochondrial outer membrane permeabilization; MSH2, mutS homolog 2; mTOR, mammalian target of rapamycin; NER, nucleotide excision repair; NSCLC, non-small cell lung carcinoma; OS, overall survival; PARP1, poly(ADP-ribose) polymerase 1; PDXK, pyridoxal kinase; PPARGC1B, peroxisome proliferator-activated receptor $\gamma$, coactivator $1 \beta$; PTPC, permeability transition pore complex; RAF1, v-raf-1 murine leukemia viral oncogene homolog 1; ROS, reactive oxygen species; SNP, single-nucleotide polymorphism; TLS, translesion synthesis; TSCC, tongue squamous cell carcinoma; USP1, ubiquitin specific peptidase 1; VDAC1, voltage-dependent anion channel 1

Received 02.9.13; revised 23.9.13; accepted 26.9.13; Edited by B Zhivotovsky
} 


\section{Facts}

- A large fraction of human malignancies rapidly becomes (or intrinsically is) insensitive to the cytostatic/cytotoxic effects of cisplatin.

- Cisplatin resistance is generally multifactorial, that is, it relies on the activation of multiple, non-redundant molecular or cellular circuitries.

- Throughout the past two decades, a number of systems biology studies has been performed to obtain additional insights into cisplatin resistance.

- The results of such an intense wave of investigation may promote the development of strategies to circumvent this clinically relevant hurdle.

\section{Open Questions}

- The precise molecular mechanisms whereby cisplatin exerts antineoplastic effects have not yet been elucidated.

- In particular, it remains unclear to which extent the cytoplasmic and nuclear events elicited by cisplatin contribute to its cytostatic/cytotoxic activity.

- Moreover, the possibility that cisplatin resistance may originate (at least in part) from cell-extrinsic (stromal or immune system-related) mechanisms has not yet been investigated in detail.

First described by the Italian chemist Michele Peyrone as early as in 1845, cis-diamminedichloroplatinum(II) (CDDP, best known as cisplatin or cisplatinum), is the founding member of a class of antineoplastic agents born in the second half of the 19th century around the peculiar atomic configuration of platinum. ${ }^{1,2}$ More than 120 years had indeed to pass from Peyrone's observations for the American chemist Barnett Rosenberg to characterize the robust antiproliferative effects of CDDP, first in Escherichia colicultures, then in solid and hematopoietic tumor xenografts. ${ }^{3,4}$ Rosenberg's findings initiated an intense wave of preclinical and clinical investigation aimed at elucidating not only the molecular mechanisms that underpin the cytostatic/cytotoxic effects of CDDP, but also its safety and therapeutic profile. ${ }^{5-7}$ Such an experimental effort culminated in 1978 with the approval of CDDP by the US Food and Drug Administration (FDA) for use in testicular and bladder cancer patients. ${ }^{7}$ Since then, CDDP has been licensed worldwide for the treatment of multiple other solid neoplasms, including head and neck, lung, colorectal and ovarian cancers. ${ }^{5,8,9}$ Thus, during the last 35 years, several millions of cancer patients have received CDDP-based antineoplastic regimens, either as part of consolidated therapeutic procedures or in the context of clinical studies. Unfortunately, CDDP-based chemo (radio)therapy was often destined to fail.

As a matter of fact, CDDP is highly efficient only against testicular germ cell cancer, leading to a durable complete remission in $>80 \%$ of the patients. ${ }^{10,11}$ Conversely, the clinical responses elicited by CDDP-based chemo(radio) therapeutic regimens in patients affected by other solid tumors (e.g., ovarian carcinoma) are temporary and vanish

as malignant cells become chemoresistant. Moreover, a significant fraction of lung, prostate and colorectal cancer patients bears neoplastic lesions that are intrinsically resistant to the cytostatic/cytotoxic activity of CDDP. ${ }^{12-14}$ Thus, although the use of CDDP (which is generally administered i.v. as a short-term infusion in physiological saline) has been associated with mild-to-moderate nephrotoxic, neurotoxic, cardiotoxic and ototoxic side effects, ${ }^{7,15}$ chemoresistance (be it intrinsic or acquired) constitutes the most prominent obstacle against the use of this drug. The biological reasons underlying the exquisite sensitivity of testicular germ cell cancers to CDDP have not been completely elucidated. Indeed, although defects in several DNA repair pathways (see below) have been associated with improved disease outcome in CDDP-treated testicular germ cell cancer patients, ${ }^{16-19}$ additional hitherto unidentified factors are likely to influence this phenomenon.

In the early 1980s, investigators and clinicians began to refocus their attention on the development of CDDP derivatives that would elicit robust therapeutic responses accompanied by clinically manageable side effects. Such an effort led to the discovery of two additional platinum derivatives that are nowadays approved by FDA for use in cancer patients: cis-diammine (cyclobutane-1,1-dicarboxylate- $O, O$ ) platinu$\mathrm{m}$ (II) (carboplatin) and [(1R,2R)-cyclohexane-1,2-diamine] (ethanedioato- $O, O^{\prime}$ )platinum(II) (oxaliplatin). ${ }^{20,21}$ The former has been licensed in 1989 for the treatment of ovarian cancer, ${ }^{20}$ whereas the latter has entered clinical practice in 2002, as part of a 5-fluorouracil (5-FU)- and folinic acidcontaining cocktail (the so-called FOLFOX regimen) that is routinely employed as a neo-adjuvant or adjuvant intervention in colorectal cancer patients. ${ }^{21}$ Carboplatin and CDDP exert antineoplastic effects via very similar, if not undistinguishable, mechanisms, reflecting the fact that the active forms of these drugs are identical. Still, carboplatin appears to be less nephro- and neurotoxic than CDDP, perhaps reflecting its reduced biological potency. ${ }^{22}$ Conversely, oxaliplatin and CDDP constitute two chemically distinct entities and as such exhibit distinct pharmacological and immunological properties. ${ }^{23-25}$ Nonetheless, a significant proportion of CDDPinsensitive tumors is resistant not only to carboplatin but also to oxaliplatin as well as to a large array of antineoplastic agents with a completely unrelated mechanism of action. ${ }^{26-36}$ These observations, which reflect the multilevel and multifactorial nature of CDDP resistance (see below), have fostered the development of additional platinum derivatives, including amminedichloro(2-methylpyridine)platinum (picoplatin) and (OC-6-43)-bis(acetato)amminedichloro(cyclohexylamine)platinum (satraplatin). As it stands, however, neither picoplatin- nor satraplatin-containing regimens provide consistent advantages over CDDP-, oxaliplatin- and carboplatinbased chemotherapy. ${ }^{37-40}$ Thus, the interest in developing novel platinum derivatives as well as clinically applicable strategies to increase the sensitivity of human neoplasms to CDDP remains high.

In this review, we summarize the mechanisms whereby CDDP exerts antineoplastic effects as well as the major determinants of CDDP resistance, laying special emphasis on recent systems biology studies aimed at avoiding or overcoming this crucial clinical issue. 


\section{Mode of Action}

CDDP is chemically inert until one or both of its cis chloro groups are replaced by water molecules. ${ }^{41,42}$ Such an 'aquation' occurs spontaneously in the cytoplasm, presumably due to the relatively low concentration of chloride ions ( $\sim 2-10 \mathrm{mM}$, as compared with $\sim 100 \mathrm{mM}$ in the extracellular space). ${ }^{43,44}$ Mono- and bi-aquated forms of CDDP are highly electrophilic and hence prone to form covalent bonds with methionine as well as with a large panel of cysteine-containing peptides and polypeptides, including reduced glutathione (GSH) and metallothioneins. ${ }^{45}$ The interaction between aquated CDDP and endogenous nucleophiles has dual consequences. On one hand, it depletes the cytosol of reducing equivalents, hence promoting the establishment of oxidative stress, which may have direct cytotoxic effects or provoke DNA damage (see below). ${ }^{46,47}$ On the other hand, it results in the inactivation of (at least a fraction of) chemically reactive CDDP, hence functioning as a cytoprotective buffer. ${ }^{12,48}$

Upon aquation, CDDP also binds with high affinity to mitochondrial and nuclear DNA, in particular to nucleophilic N7 sites on purines, thus favoring the generation of heterotypic protein-DNA complexes as well as homotypic inter- and intra-strand DNA adducts. ${ }^{49-51}$ If limited in amount, the DNA lesions provoked by CDDP can be recognized and safely removed by several repair systems that normally operate in the context of a temporary cell cycle arrest. ${ }^{52-56}$ Conversely, when the CDDP-induced DNA damage is irreparable, either such a cell cycle arrest becomes permanent (an oncosuppressive response known as cellular senescence) $)^{57,58}$ or cells become committed to die, most often via mitochondrial apoptosis. ${ }^{59-64}$ Both these processes can be initiated by the sequential activation of ATM- and RAD3-related protein (ATR, a sensor of DNA damage) and checkpoint kinase 1 (CHEK1, its major downstream effector), eventually resulting in the stabilizing phosphorylation of the oncosuppressor protein p53. ${ }^{65-69}$ A precise description of the molecular mechanisms whereby an excess of DNA lesions promotes widespread mitochondrial outer membrane permeabilization (MOMP), and hence cell death, exceeds the scope of this review and can be found in other publications. ${ }^{65-67,70,71}$

Importantly, it is now clear that the cytostatic/cytotoxic effects of CDDP do not represent a mere consequence of its genotoxic activity, but originate from both nuclear and cytoplasmic signaling pathways. ${ }^{48,72}$ In line with this notion, (i) only $\sim 1 \%$ of intracellular CDDP forms covalent bonds with nuclear DNA ${ }^{73}$ and (ii) CDDP (as well as oxaliplatin) exerts prominent cytotoxic effects in enucleated cells (cytoplasts). ${ }^{51,74-78}$ The molecular mechanisms that underlie the cytotoxic potential of cytoplasmic CDDP are poorly understood, yet may involve: (i) the accumulation of reactive oxygen species (ROS) and nitric oxide (NO), which not only exacerbate CDDP genotoxicity but also exert direct cytotoxic effects by favoring the opening of the so-called permeability transition pore complex (PTPC) $;^{70,79,80}$ (ii) the transduction of a MOMP-stimulatory signal via the pro-apoptotic BCL-2 family member BAK1, the PTPC component voltage-dependent anion channel 1 (VDAC1) and the BAK1 homolog BAX; ${ }^{81,82}$ (iii) the activation of a cytoplasmic pool of p53 that is capable of promoting MOMP via various mechanisms ${ }^{83-86}$ and (iv) in specific cellular models (see below), the establishment of an endoplasmic reticulum (ER) stress response. ${ }^{77,87}$

The relative contribution of all these nuclear and cytoplasmic effects to the cytostatic/cytotoxic activity of CDDP remains to be deciphered and may exhibit a consistent degree of context dependency (Figure 1).

\section{Mechanisms of Resistance}

We have recently discussed the molecular mechanisms that reduce the sensitivity of malignant cells to CDDP, and classified them based on functional and hierarchical parameters. In particular, we proposed that CDDP resistance can surge from alterations (i) in processes that precede the binding of CDDP to its actual targets, including DNA and cytoplasmic structures (pre-target resistance), (ii) directly related to the molecular damage provoked by CDDP (on-target resistance), (iii) in the lethal signaling pathways triggered by such molecular lesions (post-target resistance) and (iv) influencing molecular circuitries that are not (or at least have not yet been) intimately associated with CDDPelicited signals (off-target resistance). ${ }^{48}$

Pre-target resistance. CDDP resistance can develop along with alterations that reduce the amount of aquated CDDP forms in the cytoplasm. Although for a long time CDDP has been believed to get access to the cytoplasmic compartment by passively diffusing across the plasma membrane, ${ }^{42,88}$ it is now clear that the majority of CDDP is actively moved in and out of the cell by copper transporters. In particular, copper transporter 1 (CTR1) has turned out to mediate a significant fraction of CDDP intake, ${ }^{89-93}$ whereas ATPase, $\mathrm{Cu}^{2+}$ transporting, $\beta$ polypeptide (ATP7B), a $\mathrm{Cu}^{2+}$-extruding P-type ATPase involved in the pathogenesis of Wilson's disease, ${ }^{94}$ plays a significant role in CDDP export. ${ }^{90,95}$ In line with this notion, alterations in the expression level, subcellular localization and/or functionality of CTR1 and ATP7B have been associated with CDDP resistance, both in preclinical models and in cancer patients. ${ }^{90,91,93,96-102}$ Promising (though very preliminary) results from a pilot clinical trial investigating the safety and chemosensitizing potential of trientine (a copper chelator) plus platinum-based chemotherapy in advanced cancer patients (NCT01178112) have recently been disseminated. ${ }^{102-104}$

Other plasma membrane transporters have been suggested to contribute to the extrusion of CDDP (hence promoting CDDP resistance in preclinical as well as clinical settings), notably ATP-binding cassette, subfamily $C$ (CFTR/MRP), member 2 (ABCC2), best known as multidrug resistance-associated protein 2 (MRP2) ${ }^{105-109}$ and ATPase, class VI, type 11B (ATP11B). ${ }^{110}$ Moreover, CDDP-resistant cancer cells may exhibit increased levels of GSH, the enzyme that catalyzes GSH synthesis (i.e., $\gamma$-glutamylcysteine synthetase), the enzyme that conjugates CDDP with GSH (i.e., glutathione S-transferase), or metallothioneins. ${ }^{111-114}$ Although none of these alterations has been shown to be clinically relevant, all of them may contribute to pre-target resistance by incrementing the capacity of the cytoplasmic CDDP buffer. 


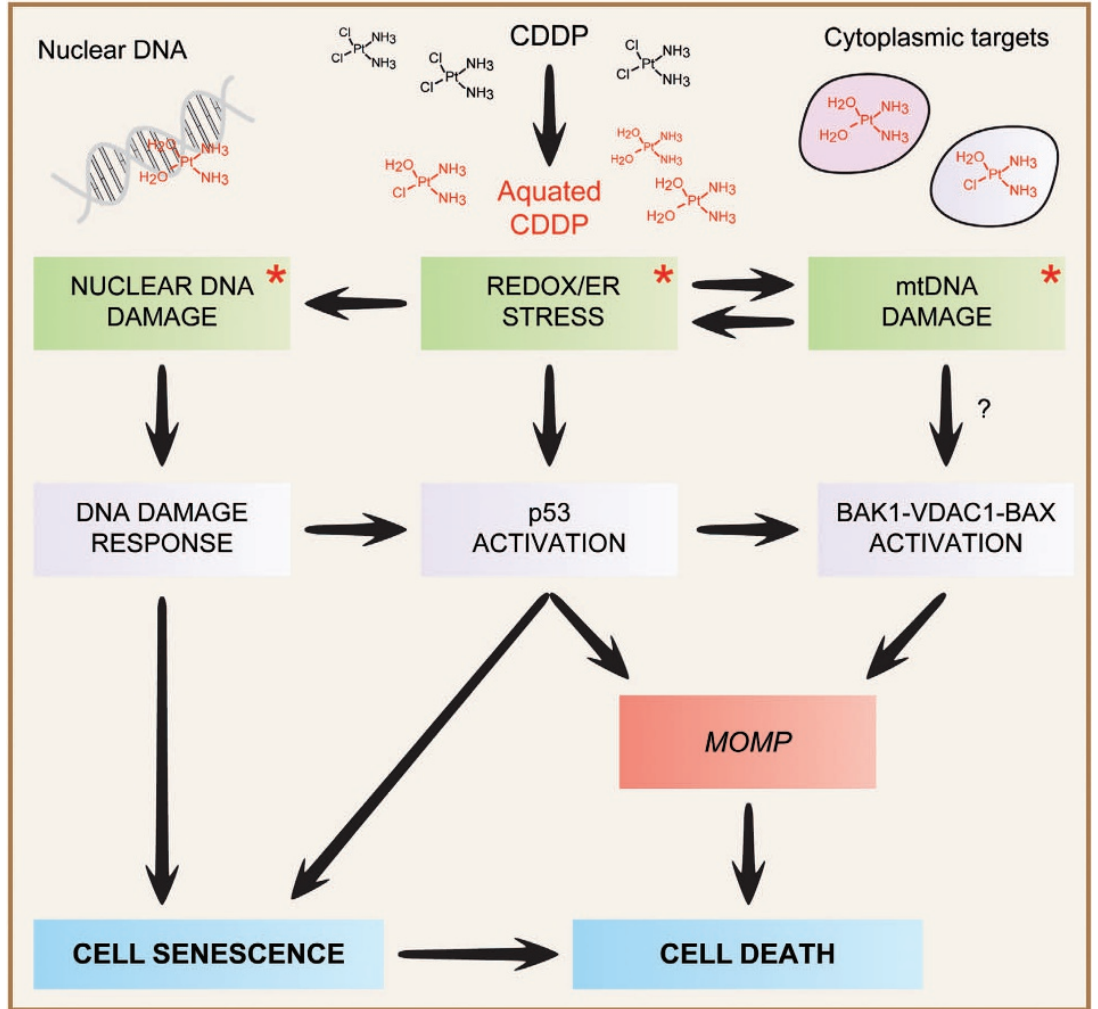

Figure 1 Mode of action of cisplatin. As a result of the reduced cytoplasmic concentration of chloride ions, intracellular cisplatin (CDDP) is rapidly 'aquated', hence acquiring a pronounced electrophilic reactivity. Aquated CDDP binds with high affinity to nuclear DNA, in particular to nucleophilic N7 sites on purines, thereby promoting the activation of the DNA damage response. In addition, CDDP can physically interact with several cytoplasmic nucleophiles, including mitochondrial DNA (mtDNA) as well as multiple mitochondrial and extramitochondrial proteins, hence (i) favoring the establishment of oxidative and reticular stress; (ii) eliciting a signal transduction cascade that involves the pro-apoptotic BCL-2 family members BAK1 and BAX, as well as voltage-dependent anion channel 1 (VDAC1) and (iii) activating the cytoplasmic pool of p53. The relative contribution of these nuclear and cytoplasmic modules to the cytostatic/cytotoxic activity of CDDP remains to be precisely elucidated and may exhibit an elevated degree of context dependency. Asterisks tag the primary consequences of CDDP reactivity. ER, endoplasmic reticulum; MOMP, mitochondrial outer membrane permeabilization

On-target resistance. The sensitivity of cancer cells to the cytostatic/cytotoxic effects of CDDP is limited in the presence of a proficient DNA repair apparatus. In particular, the nucleotide excision repair (NER) system is believed to resolve the majority of DNA lesions provoked by CDDP, ${ }^{53,54}$ although components of the mismatch repair (MMR) machinery have also been implicated in this process (at least in its detection, as opposed to resolution, phase). ${ }^{55}$ In line with this notion, an increased NER proficiency has been associated with CDDP resistance in vitro, in murine models as well as in cohorts of cancer patients. ${ }^{115-123}$ Convenient biomarkers for assessing NER proficiency in human tumors are still missing, as the actual predictive value of excision repair cross-complementing rodent repair deficiency, complementation group 1 (ERCC1) expression levels (first proposed in 2006), ${ }^{118}$ has recently been reconsidered. ${ }^{124}$ The MMR system is believed to detect DNA adducts caused by CDDP, engage in their repair and ultimately fail, thus transmitting a pro-apoptotic signal. ${ }^{125}$ Accordingly, genes encoding MMR components such as mutS homolog 2 (MSH2) and mutL homolog 1 (MLH1) are frequently mutated or downregulated in the context-acquired CDDP resistance. ${ }^{126-129}$ Moreover, non-small cell lung carcinoma (NSCLC) lesions expressing high MSH2 levels exhibit an improved prognosis upon surgical resection (in the absence of adjuvant chemotherapy). ${ }^{130}$ Thus, high expression levels of MMR components may exert a positive influence both on the propensity of chemotherapynaive tumors to relapse (perhaps because MMR limits the accumulation of additional genetic alterations) and on the probability that neoplasms exposed to CDDP become chemoresistant. MLH1 mutations are also associated with increased rates of translesion synthesis (TLS), the process whereby DNA is replicated (by a peculiar class of polymerases) in spite of unrepaired lesions. ${ }^{131}$ In line with this notion, defects in TLS polymerases including polymerase (DNA-directed), $\eta$ (POLH) and REV3-like, polymerase (DNA directed), $\zeta$, catalytic subunit (REV3L) have been linked to increased CDDP sensitivity in vitro. ${ }^{132-135}$ However, compelling clinical evidence in support of the translational relevance of these findings is elusive.

CDDP-elicited DNA adducts can engender double-strand breaks (DSBs), which are normally repaired along with DNA synthesis (or shortly after) via homologous recombination (HR) ${ }^{136}$ Accordingly, HR-deficient neoplasms, such as those bearing loss-of-function mutations in the genes encoding breast cancer 1, early onset (BRCA1) or breast cancer 2, early onset (BRCA2), ${ }^{137,138}$ are generally more susceptible to the genotoxic effects of CDDP than HR-proficient cancers of the same type. ${ }^{139-141}$ Moreover, the appearance of compensatory mutations in BRCA1 and BRCA2 that restore the functionality of HR has been show to favor CDDP resistance 
in breast carcinoma cells. ${ }^{142}$ Mutations of this type not only have been associated with the resistance of ovarian carcinoma to platinum-based chemotherapy ${ }^{142,143}$ but also appear to influence the sensitivity of pancreatic and ovarian neoplasms to inhibitors of poly(ADP-ribose) polymerase 1 (PARP1), another important regulator of DNA repair. ${ }^{144}$ Of note, while the innate resistance of pancreatic carcinoma cells to CDDP and PARP1 inhibitors resolves simultaneously in response to HR-restoring $B R C A 2$ mutations, ${ }^{143}$ we have recently reported that NSCLC cells cultured for prolonged periods in the presence of subtoxic amounts of CDDP often (but not always) manifest a constitutive hyperactivation of PARP1, hence becoming susceptible to pharmacological or genetic PARP inhibition. ${ }^{145}$ In line with these notions, the concomitant administration of CDDP and PARP inhibitors appears to elicit at least additive antineoplastic effects, in vitro and in vivo. ${ }^{146-148}$

Although the identity of the cytoplasmic components that account for the extranuclear toxicity of CDDP has only recently begun to emerge, these molecules as well as the enzymatic systems that regulate their preservation/turnover may also be involved in the development of on-target CDDP resistance. $^{72}$ So far, only a few extranuclear CDDP-binding partners have been identified, including near-to-ubiquitous (e.g., valosin-containing protein), as well as mostly cytosolic (e.g., myosin Ila, HSP90), ribosomal (e.g., ribosomal protein L5), reticular (e.g., calreticulin) and mitochondrial components (e.g., mitochondrial DNA, VDAC1). ${ }^{51,149}$ Remarkably, human NSCLC cells developing CDDP resistance as they are exposed for long periods to sublethal doses of the drug appear to be positively selected for specific mitochondrial DNA mutations, resulting in partial defects of the respiratory chain. ${ }^{150,151}$ Two mechanisms that may account for this effect are the compensatory stimulation of mitochondrial biogenesis by retrograde mitochondrio-nuclear signaling and the activation of a peroxisome proliferatoractivated receptor $\gamma$, coactivator $1 \beta$ (PPARGC1B)-dependent (but mitochondrion-independent) signal transduction cascade. ${ }^{150,152}$ Moreover, both rho ${ }^{\circ}$ cells and cells depleted of VDAC1 by RNA interference are less susceptible to CDDP cytotoxicity than their wild-type counterparts. ${ }^{51,81}$ In line with this notion, the transfection-enforced overexpression of VDAC1 reportedly sensitizes carcinoma cells to cell death induction by CDDP. ${ }^{82}$ However, elevated expression levels of VDAC1 may exert broad chemosensitization effects. ${ }^{153}$ Thus, whether these observations constitute examples of bona fide on-target resistance or rather reflect the critical role of mitochondria (and in particular of the PTPC) in CDDP-elicited cell death, hence constituting examples of post-target resistance, remains an open conundrum. Along similar lines, although physical interactions between CDDP and cyclindependent kinase 2 (CDK2) have not yet been documented, CDK2 has been shown to contribute to extranuclear CDDP toxicity (by inducing ER stress, at least in some cellular models), and CDK2-deficient cells exhibit some extent of CDDP resistance. ${ }^{77,87}$

Post-target resistance. In line with the notion that regulated cell death (be it apoptotic or necrotic) is under the control of a plethora of checkpoints and safeguard mechanisms, post-target CDDP resistance may develop along with a wide panel of alterations in the systems that detect the molecular damage caused by CDDP and convert it into a lethal signal, as well as in the machinery that de facto executes cell death. ${ }^{12,48,154}$ Malignant cells are (i) intrinsically more resistant to adverse microenvironmental and intracellular cues than their non-transformed counterparts ${ }^{155,156}$ and (ii) highly prone to acquire additional genetic and epigenetic alterations. ${ }^{157,158}$ Thus, (at least some degree of) post-target resistance can be documented in most, if not all, CDDPexposed tumors. Importantly, post-target CDDP resistance is rarely (if ever) specific, rather extending to other DNAdamaging agents (including radiation), ${ }^{27,33,159}$ as well as to cytotoxic stimuli that engage a wide panel of primary targets (e.g., death receptor agonists). ${ }^{160}$

As a general rule, intracellular stress conditions (such as those elicited by CDDP) promote the rapid activation of an integrated adaptive response aimed at the re-establishment of cellular homeostasis. ${ }^{161}$ This is generally accompanied by the emission of robust anti-apoptotic cues and only when homeostasis cannot be restored (for instance, when stress conditions are excessive in intensity or duration) lethal signals are transmitted, de facto representing a mechanism for the preservation of organismal homeostasis. ${ }^{162}$ In the case of CDDP, these signals consist in (i) the switch of the DNA damage response from a cytoprotective to a cytotoxic mode, followed by the (often, but not always, p53-dependent) activation of $\mathrm{BAX}$ and $\mathrm{BAK} 1^{163}$ and (ii) the accumulation of ROS and consequent PTPC opening. ${ }^{81,164}$ Both these processes eventually promote MOMP, in turn resulting in the functional and physical breakdown of mitochondria followed by the activation of caspase-dependent and independent mechanisms of cell death. ${ }^{70,165}$ Thus, post-target CDDP resistance has been associated not only with genetic and epigenetic alterations that impair p53 signaling (in vitro, in murine tumor models as well as in several distinct clinical scenarios) $)^{11,166-170}$ but also with defects in several other pro-apoptotic signal transducers, including mitogen-activated protein kinase 14 (MAPK14, best known as $\mathrm{p}^{\mathrm{MAPK}}$ ) and $\mathrm{c}$-Jun $\mathrm{N}$-terminal kinase 1 (JNK1). ${ }^{171,172}$ Along similar lines, post-target CDDP resistance appears to be significantly influenced by the expression levels and functional status of BCL-2 family members and caspases, a class of cysteine proteases that has a major role in the execution of apoptotic cell death. ${ }^{81,173,174}$ This said, only a few of these factors have been formally correlated with CDDP resistance in clinical studies, including various $\mathrm{BCL}-2$-like proteins such as BCL-2 itself, BCL- $\mathrm{X}_{\mathrm{L}}$ and $\mathrm{MCL}-1,{ }^{175-178}$ survivin, a caspase inhibitor that is often upregulated in response to CDDP, ${ }^{179-182}$ as well as other members of the baculoviral IAP repeat-containing (BIRC) protein family. ${ }^{183}$ In line with this notion, small molecules that antagonize the anti-apoptotic effects of BCL-2-like proteins (e.g., ABT-263) as well as IAP inhibitors (e.g., YM155, LY2181308, LBW242) have been intensively investigated in clinical trials, either as standalone anticancer interventions or in combination with various chemotherapeutics including CDDP. ${ }^{184-188}$ In spite of an acceptable safety profile and promising antineoplastic activity, the clinical development of all these agents appears to stand at an impasse, at least as judged by the low rate of 
ongoing versus completed, terminated or withdrawn trials (source www.clinicaltrials.gov).

Off-target resistance. The susceptibility of cancer cells to CDDP can also be limited by off-target mechanisms, that is, molecular circuitries that deliver compensatory survival signals even though they are not directly activated by CDDP. ${ }^{48}$ For instance, the overexpression of $v$-erb-b2 avian erythroblastic leukemia viral oncogene homolog 2 (ERBB2), which is common in breast and ovarian carcinomas, ${ }^{189,190}$ has been suggested to promote CDDP resistance not only by delivering robust pro-survival signals via the $v$-akt murine thymoma viral oncogene homolog 1 (AKT1) signaling axis, but also by finely regulating the transitory cell cycle arrest that is required for the repair of CDDP-induced DNA lesions. ${ }^{191,192}$ Along similar lines, dual-specificity Y-phosphorylation-regulated kinase 1B (DYRK1B, also known as MIRK) appears to sustain CDDP resistance as it favors the expression of various antioxidant enzymes. ${ }^{193}$ By augmenting the intracellular pool of antioxidants, DYRK1B may actually reduce the susceptibility of cancer cells to CDDP via on-target, post-target as well as off-target mechanisms. ${ }^{48}$ Recently, a poorly characterized transmembrane protein (TMEM205) has been shown to favor CDDP resistance via a molecular cascade that involves the small RAS-like GTPase RAB8A. ${ }^{194,195}$ Whether this constitutes an off-target mechanism of resistance or rather reflects the inhibition of caspase- 9 by AKT1-transduced signals ${ }^{196}$ (hence representing a post-target effect) remains to be clarified. Finally, several relatively unspecific adaptive responses to stress have been implicated in CDDP resistance. Such general responses include macroautophagy and the so-called heatshock response, that is, the adaptation of cells to increased temperatures and other conditions that promote protein unfolding. ${ }^{161}$ Thus, various components of the autophagic machinery and several chaperones of the heat-shock protein (HSP) family reportedly impair the cytostatic/cytotoxic response of cultured cancer cells to CDDP. ${ }^{149,197-201}$ Moreover, the expression levels of HSP27 may constitute a predictive biomarkers of clinical responses to CDDP in esophageal squamous cell carcinoma patients. ${ }^{202}$

In conclusion, malignant cells can lose their sensitivity to CDDP owing to a wide panel of molecular and functional alterations, many of which are a priori connected to oncogenesis and tumor progression. CDDP resistance is often multifactorial, as it relies on the simultaneous activation of multiple, non-redundant molecular circuitries (Figure 2). ${ }^{48,203}$ This obviously poses a major hurdle against the development of therapeutically useful chemosensitization strategies. As summarized below, several systems biology studies have recently been undertaken to address this clinically relevant issue.

\section{Systems Biology and Cisplatin Resistance}

Throughout the last decade, a huge number of high-content and/or high-throughput studies have been initiated to tackle - by means of an empirical approach - the complex and clinically relevant problem of CDDP resistance. For illustrative purposes, these studies can be classified into three large groups: (i) genomic, transcriptomic, methylomic and proteomic approaches, investigating the correlation between CDDP resistance and gene expression/regulation or the activation of specific signal transduction pathways (in preclinical models or patient material); (ii) large-scale silencing approaches and functional screenings, determining whether the genetic or pharmacological inhibition of specific proteins alters CDDP sensitivity (in preclinical models only) and (iii) multiplex genotyping studies, assessing in a highthroughput manner whether particular (combinations of) single-nucleotide polymorphisms (SNPs) are associated with increased or reduced CDDP sensitivity (in clinical settings). Each of these approaches obviously brings about specific advantages and disadvantages, which we will not systematically discuss here (for further details please consult a recent study by $\mathrm{He}$ et al. ${ }^{204}$ ). Still, it is important to note that, with a few exceptions (including some genotyping studies), the majority of these strategies have relied on relatively reductionistic models (e.g., cultured cancer cells) or readouts (e.g., mRNA levels in whole-tumor lysates). Considering tumors as relatively homogeneous entities exclusively composed of malignant cells and attributing CDDP resistance only to cancer cell-intrinsic mechanisms (hence neglecting the prominent structural and functional impact of stromal and immune cells) appears indeed as an excessive oversimplification (see below), and may in part explain why clinically applicable strategies for restoring CDDP sensitivity are still missing. Nonetheless, these studies have provided us with ever more precise insights into the molecular mechanisms that account for CDDP resistance, at least at the cell-intrinsic level. Here, we provide an overview of recent systems biology studies (for the most part published in the last 3 years) that have significantly added to our understanding of CDDP resistance (Supplementary Table 1).

Genomic, methylomic, transcriptomic and proteomic approaches. For nearly one decade, it has been possible - and cost-efficient - to employ microarrays for quantifying (i) variations in gene copy number, by comparative genomic hybridization $(\mathrm{CGH})$, (ii) the abundance of mRNAs and (iii) the expression levels of regulatory RNA species (including microRNAs and long non-coding RNAs) in both human and murine samples. Thus, several research groups worldwide, including us, have adopted one of these approaches to get further insights into CDDP resistance. Nonetheless, the potential of these methods is intrinsically limited by the frequent lack of correlation between copy number or mRNA/microRNA expression levels and phenotype, calling for robust rounds of functional validation. ${ }^{205}$ Recently, along with the evolution of mass spectrometry and the development of high-throughput techniques for the study of post-translational protein modifications (including, but not limited to, phosphorylation and acetylation), ${ }^{206-209}$ attention has been refocused to proteomic/interactomic approaches as well as to the identification of novel signal transduction cascades that underpin CDDP resistance. In addition, great enthusiasm has been generated by the possibility to sequence the whole genome of neoplastic lesions, as first achieved for acute myeloid leukemia and quickly thereafter for various other malignancies. ${ }^{210-214}$ Further increasing the 


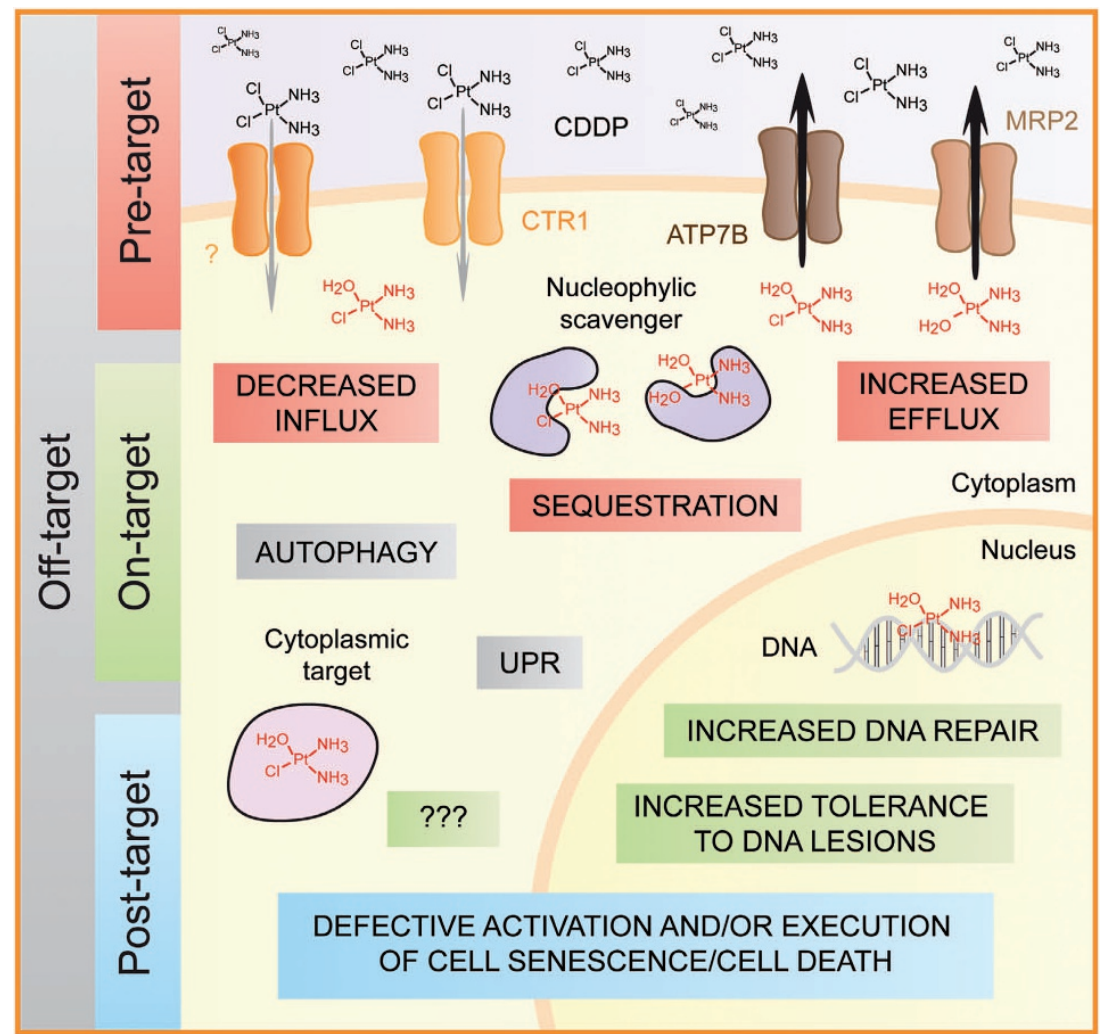

Figure 2 Molecular mechanisms of cisplatin resistance. Malignant cells can lose their sensitivity to the cytostatic/cytotoxic activity of cisplatin (CDDP) as a result of a wide panel of genetic or epigenetic defects. These alterations can (i) affect processes that precede the actual binding of CDDP to its targets (pre-target resistance); (ii) potentiate the ability of cells to repair the molecular damage caused by CDDP (on-target resistance); (iii) impair the transmission of signals that normally relay such a CDDP-induced damage to cell senescence or apoptosis (post-target resistance) or (iv) stimulate the delivery of pro-survival signals that antagonize CDDP cytotoxicity although they are normally not elicited by this drug (off-target resistance). Of note, CDDP resistance is generally multifactorial, that is, it relies on the activation of several, non-overlapping mechanisms that concur to limit the cytostatic/cytotoxic effects of CDDP at multiple levels. At least in part, this explains why efficient strategies to increase the sensitivity of human neoplasms to CDDP are still lacking in spite of a prolonged and intense wave of investigation. ATP7B, ATPase, $\mathrm{Cu}^{2+}$ transporting, $\beta$ polypeptide; CTR1, copper transporter 1; MRP2, multidrug resistance-associated protein 2; UPR, unfolded protein response. CDDP aquation is depicted in red

potential of this approach, Murtaza et al. ${ }^{215}$ have just demonstrated that advanced solid tumors can be sequenced starting from DNA molecules released by malignant cells into the plasma, de facto constituting a non-invasive liquid biopsy. Again, although these approaches can undoubtedly improve our understanding of CDDP resistance, caution should be taken while interpreting sequencing data in the absence of functional validation.

Several factors have recently been revealed or confirmed to contribute to CDDP resistance as a result of genomic, methylomic, transcriptomic and proteomic studies (Supplementary Table 1). Using CGH arrays, Cui et al. ${ }^{216}$ identified an interleukin-7 (IL-7)-dependent autocrine loop specifically activated in glioma cells that have lost their sensitivity to CDDP. By means of an integrated approach involving $\mathrm{CGH}$ arrays and transcriptomic studies, Jiffar et $a .^{218}$ demonstrated that head and neck squamous cell carcinomas (HNSCCs) can become resistant to CDDP along with the loss of KiSS-1 metastasis-suppressor (KISS1), a G protein-coupled receptor ligand that also mediates CDDPindependent oncosuppressive functions. ${ }^{217,218}$ By comparing the methylome of CDDP-sensitive and CDDP-resistant isogenic ovarian cancer cells, Yu et al. ${ }^{219}$ found that the latter exhibit not only a global decrease in the methylation of $\mathrm{CpG}$ islands but also specific alterations including the hypomethylation (which is generally associated with increased gene expression) of protein tyrosine kinase 6 (PTK6), coding for a non-receptor tyrosine kinase with prominent pro-survival functions; protein kinase $\mathrm{C} \varepsilon(P R K C E)$, encoding a $\mathrm{Ca}^{2+}$ and diacylglycerol-activated serine/threonine kinase, and BCL-2-like 1 (BCL2L1), coding for BCL- $X_{L} .{ }^{219}$ By means of a systems biology approach comprising a methylomic and a transcriptomic component, Zeller et al. ${ }^{220}$ identified a set of nine genes that are hypermethylated (resulting in decreased transcription) both in several, independent CDDP-resistant derivatives of an ovarian carcinoma cell line (i.e., A2780 cells), and in clinical samples from ovarian carcinoma patients relapsing upon platinum-based chemotherapy. Besides $M L H 1$, which is often mutated or downregulated in the context of CDDP resistance, ${ }^{126-129}$ these genes include Rho GDP dissociation inhibitor $\beta$ beta $(A R H G D I B)$, armadillo repeat containing, X-linked 2 (ARMCX2), collagen, type I, $\alpha 1$ (COL1A1), filamin A $\alpha$ (FLNA) filamin $\mathrm{C} \gamma(F L N C)$, mesodermspecific transcript (MEST), neurotensin (NTS) and proteasome (prosome, macropain) subunit, $\beta$ type, 9 (PSMB9), pointing to the existence of hitherto unexplored mechanisms whereby malignant cells can lose their sensitivity to CDDP. ${ }^{220}$ Ivanova et al. ${ }^{221}$ applied a very similar experimental strategy 
to study gastric cancer, identifying bone morphogenetic protein 4 (BMP4) as an epigenetically regulated factor that underpins CDDP (but not oxaliplatin) resistance and exerts oncogenic functions (at least in this setting) by promoting the epithelial-to-mesenchymal transition (EMT). It remains unclear whether the oncogenic activity of BMP4, similar to that of IL-7, relies on autocrine signaling circuitries.

The profound implication of the DNA repair machinery and the $\mathrm{BCL}-2$ protein family in CDDP resistance has been confirmed by a large number of recent transcriptomic studies. ${ }^{118,124,222-226}$ However, none of these factors has yet been validated as a reliable clinical predictor of CDDP sensitivity. ${ }^{124}$ Alongside, the abundance of transcripts coding for several proteins that have no obvious links with CDDPelicited signaling pathway has been correlated with clinical CDDP resistance. These factors include AKT1, eukaryotic translation initiation factor $4 \mathrm{~B}$ (EIF4B) and ribosomal protein S6 (RPS6), defining a metabolic signature linked to the activity of mammalian target of rapamycin (mTOR); ${ }^{227}$ cytochrome P450, family 4, subfamily B, polypeptide 1 (CYP4B1), choline/ ethanolamine phosphotransferase 1 (CEPT1) and charged multivesicular body protein $4 \mathrm{~A}(\mathrm{CHMP} 4 \mathrm{~A}),{ }^{228}$ as well as several proteins implicated in the EMT. ${ }^{229}$ However, whether the EMT triggers a specific pathway of CDDP resistance or these observations rather reflect the high number of genetic and epigenetic alterations that characterize advanced neoplastic lesions (underpinning their aggressiveness and chemoresistance) remains to be determined. Furthermore, by analyzing HNSCC biopsies with whole-genome microarrays and quantitative reverse transcriptase PCR cards, Tomkiewicz et al. ${ }^{230}$ delineated a 10-gene signature that predicts the response of HNSCC patients to CDDP/5FU-based induction chemotherapy. As it stands, most of these genes have not been previously implicated in CDDP resistance, although some of them code for factors that have a role in the cytoprotective response to redox stress, such as DnaJ (Hsp40) homolog, subfamily $\mathrm{A}$, member 1 (DNAJA1) and thioredoxin domain containing 9 (TXNDC9). ${ }^{230}$

By comparing the transcriptomic profile of NSCLC A549 cells exposed to cytotoxic doses of CDDP, cadmium dichloride $\left(\mathrm{CdCl}_{2}\right.$, an environmental pollutant that triggers oxidative stress-dependent apoptosis) and $\mathrm{C}_{2}$-ceramide (a plasma membrane permeant ceramide with mitochondriotoxic effects), we have recently demonstrated that CDDP elicits signaling cascades (encompassing both pro-survival and pro-death pathways) that are for the most part 'private', that is, they manifest limited overlap with the molecular mechanisms set in motion by other inducers of mitochondrial apoptosis. ${ }^{231}$ Along similar lines, by studying the microRNAome of A549 cells succumbing to CDDP, $\mathrm{CdCl}_{2}$ or $\mathrm{C}_{2}$-ceramide, we identified miR-181a and miR-630 as functional components of the molecular mechanisms that underpin CDDP toxicity and the general cytoprotective response of A549 cells to stress, respectively. ${ }^{232}$ On a similar note, several research groups have recently investigated the microRNAomic profile of CDDP-sensitive versus CDDP-resistant cancer cell lines of various origin, including glioblastoma, ${ }^{233}$ tongue squamous cell carcinoma (TSCC), ${ }^{234}$ NSCLC, ${ }^{235-238}$ hepatocellular carcinoma (HCC) ${ }^{239}$ and ovarian carcinoma. ${ }^{240,241}$ Several of these studies identified the downregulation of microRNAs that inhibit the expression of anti-apoptotic BCL-2-like proteins (e.g., miR-135 and miR497) as a prominent mechanism of CDDP resistance. ${ }^{235,236}$ In addition, a decrease in the sensitivity of cancer cells to the cytostatic/cytotoxic effects of CDDP has been associated with the upregulation of microRNAs that target the major oncosuppressive factor phosphatase and tensin homolog (PTEN), such as miR-130a and miR-93, ${ }^{240,241}$ and ERCC1, like miR$138,{ }^{237}$ as well as with the downregulation of microRNAs that normally limit the expression of cell cycle-associated proteins such as let-7b. ${ }^{233}$ Similarly, CDDP resistance in cultured A549 cells has been correlated with the downregulation of a long non-coding RNA (AK126698) that inhibits WNT/ $\beta$-catenin signaling. 238

At odds with our observations, elevated expression levels of miR-181a have been associated with a decreased (rather than increased) sensitivity of cultured HCC cells to multiple antineoplastic agents, including CDDP. ${ }^{239}$ Such an apparent discrepancy may originate from the experimental systems employed (i.e., acute response to CDDP in NSCLC cells versus stably acquired resistance in HCC cells) or reflect a context-dependent role of miR-181a. This said, elevated expression levels of miR-181 species (in the context of a 58component microRNA signature) have been shown to predict the response of gastric carcinoma patients to CDDP/5-FUbased chemotherapy. ${ }^{242}$ The precise elucidation of the molecular targets of miR-181 may provide important insights this issue. In another clinical study, the upregulation of miR$135 \mathrm{~b}$ and miR-145 in response to trimodal therapy (concurrent CDDP, irinotecan and irradiation, followed by surgery) has been associated with poor disease-free survival (DFS) among esophageal carcinoma patients, ${ }^{243}$ but the molecular mechanisms underpinning these observations have not been further investigated. Interestingly, microRNAomic studies also implicate the EMT in CDDP resistance. In particular, $\mathrm{miR}-200 \mathrm{~b}$ and miR-15b (which are downregulated in CDDP-resistant TSCC cells) turned out to actively inhibit the EMT (hence exerting oncosuppressive effects) by targeting the polycomb ring finger oncogenic factor BMI1. ${ }^{234}$ In line with this notion, reduced intratumoral levels of miR-200b or miR$15 \mathrm{~b}$ have been associated with clinical CDDP resistance and poor survival in a cohort of TSCC patients. ${ }^{234}$ Of note, the expression of several microRNAs and proteins that contribute to CDDP resistance is under the control of epigenetic mechanisms, including DNA methylation and histone acetylation. ${ }^{244-247}$ This raises the intriguing possibility that pharmacological inhibitors of DNA methyltransferases and histone deacetylases, some of which are currently approved by international regulatory agencies for use in cancer patients, may limit CDDP resistance at least in part by modulating the abundance of specific microRNAs. ${ }^{247-252}$ Robust experimental evidence in support of this hypothesis is lacking.

Various aspects of CDDP resistance have been uncovered by proteomic approaches. By combining quantitative proteomics with interaction network analyses, Chavez et al. ${ }^{253}$ demonstrated that the levels of no less than 374 proteins are altered in CDDP-resistant (as compared with wild-type, CDDP-sensitive) cervical carcinoma HeLa cells, including various components of energy-producing metabolic pathways as well as proteins involved in DNA repair and other stress 
response mechanisms. Zeng et al. ${ }^{254}$ found CDDP-insensitive NSCLC A549 cells to differ from their CDDP-susceptible counterparts in the expression levels of 9 proteins, including parkinson protein 7 (PARK7, best known as DJ-1), a transcription-modulatory and antioxidant factor implicated in the development of familiar Parkinson disease. These findings had an important clinical correlate, as elevated amounts of DJ-1 turned out to predict poor disease outcome in a cohort of 67 locally advanced NSCLC patients. ${ }^{254}$ Along similar lines, Roesch et al. ${ }^{255}$ demonstrated that melanoma cells exposed for long periods to suboptimal CDDP concentrations not only express increased levels of the histone demethylase Jumonji, AT-rich interactive domain 1 (JARID1) but also contain increased amounts of several enzymes implicated in mitochondrial respiration. Importantly, inhibition of the mitochondrial respiratory chain appears to prevent the accumulation of these slowly proliferating CDDP-insensitive cells, delineating a strategy for the selective elimination of malignant cell clones that initially resist CDDP-based chemotherapy. ${ }^{255}$ Accordingly, the response of esophageal adenocarcinoma patients to neo-adjuvant CDDP-based chemotherapy correlates with mitochondrial defects provoked by the loss of specific cytochrome c oxidase (COX) subunits. ${ }^{256}$ On a slightly different note, Vasko et al. ${ }^{257}$ investigated the acute proteomic alterations caused by therapeutic concentrations of CDDP in renal cell carcinoma cells. In this context, CDDP-treated cells were found to express increased levels of multiple cytoskeletal proteins, molecular chaperones of the HSP family and glycolytic enzymes. ${ }^{257}$ Taken together, these observations suggest that cancer cells acutely exposed to CDDP might temporarily rely on glycolysis as a source of energy (presumably reflecting the mitochondriotoxic effects of cytoplasmic CDDP), whereas the acquisition of stable CDDP resistance might require a robust respiratory activity. ${ }^{255-257}$ At least in part, this is at odds with our recent findings, indicating that CDDP resistance can be mediated by the activation of a PPARGC1B-dependent signaling pathway that is elicited by respiratory chain defects but does not depend on mitochondrial biogenesis. ${ }^{150}$ Thus, the precise contribution of glycolysis and mitochondrial respiration to the development of CDDP resistance remains to be clarified.

As an alternative to conventional whole-cell approaches, proteomic studies to elucidate CDDP resistance have been performed on enriched subcellular compartments (e.g., nuclei, mitochondria), ${ }^{258-260}$ purified components known to participate in CDDP-elicited signaling pathways (e.g., immobilized CDDP, Y-box binding protein 1), ${ }^{149,261}$ as well as on serum samples from cancer patients. ${ }^{262,263}$ The latter approach allowed for the identification of $\alpha 1$-antitripsin (a circulating protease inhibitor with anti-inflammatory functions) and S100A9 (a $\mathrm{Ca}^{2+}$-binding protein that exerts immunomodulatory effects) as possible biomarkers of clinical CDDP resistance. ${ }^{262,263}$ Moreover, CDDP resistance has been associated with immunopeptidomic alterations, that is, changes in the composition and abundance of peptides presented on the cell surface in complex with $\mathrm{MHC}$ molecules. ${ }^{260}$ This is particularly important in view of the facts that (i) several anticancer regimens operate by eliciting or boosting anticancer immunity, some of them by altering the immunopeptidome of malignant cells ${ }^{264,265}$ and that (ii) CDDP is generally considered as a non-immunogenic anticancer agent. $^{24,25}$ Thus, it is tempting to speculate that CDDP resistance might involve specific changes in the immunopeptidome of neoplastic cells as well as in the tumor microenvironment that prevent the activation of anticancer immune responses. Formal evidence in support of this hypothesis is missing.

Large-scale silencing approaches and functional screenings. In the mid 2000s, key technological advances have allowed researchers to tackle CDDP resistance with large-scale functional/empirical approaches, as opposed to high-throughput observational studies followed by low-throughput functional validation (such as the genomic, methylomic, transcriptomic and proteomic approaches described above). These developments include (but perhaps are not limited to): (i) the availability of the first genome-wide siRNA sets, at least theoretically permitting the downregulation of each mRNA encoded by the human or murine genome; ${ }^{266,267}$ (ii) the explosion of combinatorial chemistry, allowing for the generation of huge libraries of compounds for investigational purposes ${ }^{268,269}$ and (iii) the rapid diffusion of fully robotized platforms compatible with the sterile handling of 96- and 384-well plates. ${ }^{270,271}$ Thus, along with the establishment of reproducible and cost-efficient workflows, large-scale silencing approaches and ample chemical screenings have been undertaken by several groups worldwide, providing profound insights into the phenomenon of CDDP resistance. ${ }^{231,272-277}$ It should be noted that these functional/empirical approaches are not exempted from validation. Rather, primary hits must be confirmed upon (i) the exclusion of putative off-target effects and the establishment of a robust cause-effect relationship between the downregulation of a specific protein and CDDP resistance (possibly coupled to the elucidation of the underlying mechanisms) or (ii) the precise identification of the molecular target(s) through which a given chemical alters the sensitivity of cancer cells to CDDP (and again the clarification of mechanistic aspects of this phenomenon). Similar to the genomic, transcriptomic, methylomic and proteomic approaches described above, these functional/empiric approaches rely on homotypic experimental settings, mainly cultured cancer cells, de facto overlooking the notion that CDDP resistance (at least in some settings) might originate from alterations of the tumor microenvironment or systemic defects (see below). Approximately in the same period, investigators have attempted to elucidate the mechanisms that limit the sensitivity of malignant cells to CDDP by taking advantage of well-established, genetically tractable models that would be compatible with ample knockout strategies, such as Saccharomyces cerevisiae, Schizosaccharomyces pombe and Dictyostelium discoideum. ${ }^{89,231,278-281}$ Although these genetic approaches are cost-efficient and straightforward, hits must be subjected to multiple, intense rounds of cross-species functional validation.

We have been working intensively along these lines to obtain clinically relevant insights into CDDP resistance. As a result of a genome-wide siRNA screening approach, we identified the metabolism of vitamin $\mathrm{B} 6$ as a central regulator of the response of cancer cells to a wide array of nutritional, 
physical and chemical stress conditions, including the administration of CDDP. ${ }^{272,282}$ In particular, we found that the cytotoxic response of a large panel of cancer cells to stress is significantly exacerbated in the presence of a cell permeant B6 vitamer, pyridoxine. Such an effect was only observed when cells expressed pyridoxal kinase (PDXK), the enzyme that generates the bioactive form of vitamin B6 (pyridoxal-5phosphate). In line with this notion, the downregulation of PDXK conferred a significant degree of protection from stress to cancer cells, while that of pyridoxal phosphatase (PDXP), the enzyme that degrades bioactive vitamin B6, caused a robust increase in the cytotoxicity of several stimuli. ${ }^{272}$ Importantly, NSCLC patients (from two distinct cohorts, one from Europe and one from North America) bearing lesions that expressed high levels of PDXK had an improved disease-free and overall survival (OS) than individuals affected by tumors with low PDXK levels, irrespective of therapy. ${ }^{272}$ Of note, the prognostic value of the vitamin B6 metabolism among NSCLC patients was clear when PDXK levels were quantified by immunohistochemistry (IHC) in malignant cells, but neither when the adjacent, non-malignant lung tissue was analyzed (implying that the effect of vitamin B6 on disease progression originates in the tumor) nor when the amount of the PDXKcoding mRNA was assessed in tumor biopsies (perhaps suggesting that PDXK is subjected to a relevant degree of post-transcriptional regulation). ${ }^{272}$ Although the precise molecular mechanisms whereby vitamin B6 sensitizes malignant cells to adverse conditions remain unclear, we found that the administration of pyridoxine (i) facilitates the establishment of oxidative stress (presumably explaining the influence of vitamin B6 on tumor progression) ${ }^{272}$ and (ii) promotes the intracellular accumulation of CDDP (at least in part accounting for the ability of vitamin B6 to promote the cytotoxicity of CDDP, in vitro and in vivo). ${ }^{273}$ Both these effects were strictly dependent on the presence of PDXK, implying that they both are mediated by pyridoxal-5-phosphate..$^{272,273,282}$ Of note, the same study led us to identify 84 additional factors that influence the response of NSCLC to CDDP, including lipase, hepatic (LIPC) ${ }^{283}$ Similar to those of PDXK, the intratumoral levels of LIPC turned out to positively correlate with disease outcome (independent of several other prognostic factors, including PDXK expression) in two distinct cohorts of NSCLC patients. ${ }^{283}$ Moreover, in one of these relatively small cohorts, LIPC expression levels tended to have a predictive (as opposed to merely prognostic) value. ${ }^{283}$ Thus, although validation in large patient cohorts is still pending, LIPC expression levels may constitute a biomarker that allows for the identification of patients who obtain a true clinical benefit from the administration of platinum-based chemotherapy. This said, the molecular mechanisms through which LIPC influences tumor progression (and perhaps response to chemotherapy) remain obscure.

A few other groups have undertaken global silencing approaches to discover novel factors involved in CDDP resistance. For instance, Ho et al. ${ }^{277}$ found that the GTPase RAS homolog family member $\mathrm{J}$ (RHOJ) and p21 protein (CDC42/RAC)-activated kinase 1 (PAK1) render melanoma cells resistant to DNA-damaging agents (including dacarbazine and CDDP) by uncoupling ATR from its downstream effectors, resulting in the expression of the survival gene SRY (sex determining region Y)-box 10 (SOX10). By focusing this strategy on lipid and protein kinases, Guerreiro et al. ${ }^{284}$ identified a set of six factors involved in the decreased sensitivity of medulloblastoma cells to CDDP, including ATR, membrane protein, palmitoylated 2 (MPP2), phosphatidylinositol 4-kinase, catalytic, $\alpha$ (PI4KA), phosphatidylinositol-4,5-bisphosphate 3-kinase, catalytic subunit $\gamma$ (PIK3CG), STE20-related kinase adaptor $\alpha$ (STRADA, a pseudokinase also known as LYK5) and WNK lysine-deficient protein kinase 4 (WNK4). A kinome-wide siRNA screen allowed Salm et al. ${ }^{276}$ to identify fibroblast growth factor receptor 2 (FGFR2) as an important determinant of CDDP resistance in neuroblastoma. FGFR2 turned out to decrease the sensitivity of neuroblastoma cells to CDDP via an autocrine loop promoting the expression of BCL-2 and BCL-X $X_{L}$. Moreover, the expression levels of FGFR2 were shown to have a clinical relevance, as they correlated with the amplification of $v$-myc avian myelocytomatosis viral oncogene neuroblastoma-derived homolog (MYCN) and advanced disease stage. ${ }^{276}$ Of note, silencing approaches can also be implemented by means of microRNA mimics. By screening a panel of these reagents, Pouliot et al. ${ }^{285}$ demonstrated that several microRNAs of the miR-15 family, including miR-15a, miR-15b, miR-16, miR-16-1* and miR-424*, alter the sensitivity of epidermoid carcinoma cells to CDDP as they regulate the expression of cell cycle-associated kinases.

Large chemical libraries have been screened for the presence of compounds that may increase the susceptibility of malignant cells to the cytostatic/cytotoxic effects of CDDP. Using this approach, Chen et al. ${ }^{275}$ identified pimozide and GW7647, two distinct inhibitors of the deubiquitinase complex assembled by ubiquitin specific peptidase 1 (USP1) and WD repeat domain 48 (WDR48, also known as UAF1), as putative chemosensitizers in NSCLC cells. As the USP1/UAF1 complex is involved in TLS, pimozide and GW7647 may operate by limiting the ability of cancer cells to bypass CDDPinduced DNA lesions. By screening a validated library of kinase inhibitors, Wong et al. ${ }^{286}$ demonstrated that the inhibition of several signal transducers including AKT1, mTOR, NF- $\kappa \mathrm{B}$, transforming growth factor $\beta$ receptor 1 (TGFBR1), phosphoinositide-3-kinase (PI3K) and various MAPKs sensitizes basal-like breast carcinoma cells to the toxic effects of CDDP. Specifically, the mTOR inhibitor rapamycin was shown to synergize with CDDP in the killing of basal-like MDA-MB-468, MDA-MB-231 and HCC1937 cells, but not luminal-like T47D or MCF-7 cells, owing to the induction of the p53-related protein p73. ${ }^{286}$ Jacquemont et al. ${ }^{274}$ tested > 16000 compounds for their ability to inhibit the formation of DNA damage foci triggered by irradiation or CDDP, identifying a dozen molecules that sensitize ovarian cancer cells to the cytotoxic effects of the latter. These molecules include several inhibitors of the Fanconi anemia (FA) DNA repair pathway (which coordinates HR and TLS for the repair of interstrand crosslinks) and indeed were confirmed to exacerbate the cytostatic/cytotoxic potential of CDDP in FA-proficient but not in FA-deficient ovarian cancer cells. Finally, Garnett et al. ${ }^{287}$ recently undertook a large screen to identify genes associated with the cellular responses to most anticancer agents available to date. To this aim, 130 drugs currently approved by regulatory agencies for use in cancer patients or under clinical development were 
tested on several hundred cancer cell lines, representing much of the tissue-type and genetic diversity of human tumors. This systematic screening approach generated several unexpected findings, including the extremely high sensitivity to both PARP inhibitors and CDDP of Ewing's sarcoma cells harboring a translocation that involves EWS RNA-binding protein 1 (EWSR1) and Fli-1 proto-oncogene, ETS transcription factor $(F L / 1){ }^{287}$

Functional screenings recently performed in genetically tractable organisms have also unveiled various aspects of CDDP resistance. For instance, by screening the clonogenic potential of a collection of $S$. cerevisiae mutants exposed to an overtly toxic amount of CDDP, we demonstrated that the molecular cascades elicited by CDDP, $\mathrm{CdCl}_{2}$ and $\mathrm{C}_{2}$-ceramide in yeast exhibit very limited overlaps. ${ }^{231}$ Indeed, none of the $S$. cerevisiae mutants tested was protected from the cytostatic/cytotoxic potential of all these compounds. Of note, $\Delta$ por2 cells, lacking one isoform of the yeast ortholog of human VDAC1, turned out to be specifically protected against CDDP cytotoxicity, indicating that the molecular mechanisms that underlie CDDP resistance are phylogenetically conserved. ${ }^{231}$ Upon the development of a high-resolution high-throughput screening (HTS) platform, Sletta et al. ${ }^{281}$ tested the response of $>1400 \mathrm{~S}$. cerevisiae deletion mutants to three distinct DNA-damaging agents, namely, methyl methanesulphonate, 5-FU and CDDP, identifying MAPK7 (also known as ERK5) as an evolutionarily ancient regulator of the DNA damage response that also operates in human cells. Using 2359 non-essential haploid deletion mutants of the fission yeast $S$. pombe, Gatti et al. ${ }^{280}$ identified no less than 13 distinct gene products involved in the ubiquitin-proteasome system whose absence increases (3 proteins) or decreases (10 proteins) CDDP sensitivity. Although these authors did not validate their findings in mammalian systems, we and others confirmed the implication of the proteasome in the response of human cells to CDDP. ${ }^{220,272}$

Multiplex genotyping studies. During the last decade, dozens of studies have been carried out to determine whether SNPS affecting one or more genetic loci would influence the natural course of multiple neoplasms (leading to the identification of prognostic biomarkers) or the propensity of neoplastic lesions to respond to specific therapeutic regimens, including CDDP-based chemotherapy (resulting in the characterization of predictive biomarkers). ${ }^{288-291}$ This approach has obvious clinical implications because it may lead to the identification of patient subgroups that will benefit from treatment, and hence allow for the implementation of personalized medicine. ${ }^{292}$ Moreover, the identification of genetic backgrounds that influence the antineoplastic activity of CDDP would have one major advantage as compared with most strategies for the elucidation of resistance discussed above: it would intrinsically consider all possible cancer cell-extrinsic factors that may impact on this phenomenon, irrespective of whether they have previously been described or not. However, until recently, genotyping studies could only focus on SNPs affecting one (or a few) protein(s) at the same time, owing to technical limitations. Thus, near-to-invariably, these approaches would study SNPs known or expected to influence cellular or organismal processes linked to CDDP sensitivity, such as CDDP extrusion (e.g., SNPs affecting ABCC2), DNA damage-elicited signal transduction (e.g., SNPs affecting ERCC1), apoptosis (e.g., SNPs affecting caspases) or immune responses (e.g., SNPs affecting cytokines or their receptors). ${ }^{293-298}$ This limitation has nowadays been circumvented by the introduction of technical platforms that allow for the simultaneous determination of up to 384 different SNPs in one single assay. ${ }^{299-301}$

A few genotyping studies of this type have already been performed to obtain insights into the organismal aspects of CDDP resistance. Tan et al. ${ }^{302}$ reported that two SNPs affecting the expression levels of death-associated protein kinase 3 (DAPK3) and methyltransferase like 6 (METTL6) influenced disease outcome in 222 small cell lung carcinoma and 961 NSCLC patients treated with platinum-based therapy. Accordingly, the knockdown of DAPK3 and METTL6 was shown to significantly decrease CDDP sensitivity in lung carcinoma cells. ${ }^{302}$ By adopting a similar approach, Wheeler et al. $^{303}$ tested the association between 2 million SNPs and the response of lymphoblastoid cell lines (LCLs) derived from 83 individuals of African American descent to cytarabine, 5 '-deoxyfluorouridine, carboplatin and CDDP. This study led to the identification of 41 genes that putatively influence the response of African Americans to CDDP-based chemotherapy. Notably, the set of SNPs associated with the sensitivity of LCLs to CDDP exhibited some degree of overlap with that linked to carboplatin susceptibility, reinforcing the notion that platinum derivatives activate similar, but not identical, signal transduction cascades. ${ }^{303}$ More recently, the same authors expanded their analysis to a total of 608 LCLs and $>3$ million SNPs, reporting a robust association between CDDP susceptibility and a SNP upstream of keratin 16 pseudogene 2 (KRT16P2) as well as a link between the sensitivity of LCLs to CDDP and SNPs affecting BCL2, ERCC2, ERCC6, glutathione S-transferase $\mu 1$ (GSTM1) and glutathione S-transferase $\theta 1$ (GSTT1). ${ }^{304} \mathrm{Li}$ et al. ${ }^{305}$ analyzed the association between 894 SNPs affecting 70 genes involved in glutathione metabolism, DNA repair, cell cycle and epidermal growth factor receptor (EGFR) signaling and disease outcome among 1076 NSCLC patients treated with various platinumbased chemotherapeutic regimens. Globally, SNPs affecting glutathione synthetase (GSS) and mitogen-activated protein kinase kinase kinase 1 (MAP3K1) were linked to poor OS. Moreover, SNPS affecting MAP3K1 turned out to negatively influence the OS of NSCLC patients treated with platinum derivatives plus a taxane, whereas SNPs in the $v$-raf-1 murine leukemia viral oncogene homolog 1 (RAF1) had an opposite effect on the OS of this patient subgroup. Along similar lines, SNPs involving RAF1 (as well as glutathione peroxidase 5, GPX5) were associated with improved OS among patients receiving platinum derivatives plus gemcitabine. Conversely, SNPs affecting GPX7 and neuroblastoma RAS viral ( $v$-ras) oncogene homolog (NRAS) had a negative influence on OS in these individuals. ${ }^{305} \mathrm{Wu}$ et al. $^{306}$ studied the influence of 307260 distinct SNPs on the survival of three distinct cohorts of $(327,315$ and 420) advanced-stage NSCLC patients who received platinum-based chemotherapy with or without irradiation, identifying a relatively reproducible (though not absolute) association between SNPs in chemokine-like 
receptor 1 (CMKLR1) and sortilin-related VPS10 domain containing receptor 2 (SORCS2) and poor OS. Along similar lines, Hu et al. ${ }^{307}$ performed a fast-track genotyping study on three distinct cohorts of $(307,228$ and 340) NSCLC patients receiving first-line platinum-based chemotherapy, finding an association between three SNPs (rs7629386 at 3p22.1, rs969088 at 5p14.1 and rs3850370 at 14q24.3) and poor OS as well as a link between two SNPs (rs41997 at 7q31.31 and rs12000445 at 9p21.3) and improved OS. These studies and others of a similar type to come may provide significant insights into the organismal aspect of CDDP resistance.

\section{Concluding Remarks}

Throughout the last 4 decades, several millions of cancer patients have been treated with CDDP-based chemo (radio)therapeutic regimens. Exception made for individuals bearing testicular germ cell tumors, most of these patients only obtained temporary clinical benefits, which were destined to vanish along with the progressive transition of malignant cells from a chemosensitive to a chemoresistant state. Thus, even though CDDP provokes moderate-to-severe adverse effects in a fraction of patients, the most prominent hurdle related to the use of CDDP in the clinical practice is posed by the elevated incidence of chemoresistance, be it innate or acquired. An intense wave of preclinical and clinical investigation aimed at developing strategies to restore the sensitivity of human neoplasms to the cytostatic/cytotoxic effects of CDDP has been initiated worldwide in the late 1970s. Reflecting the huge clinical and socioeconomic impact of CDDP resistance, such an investigational effort has not yet come to an end. Indeed, although several strategies have been devised to circumvent CDDP resistance in cancer patients, including (but not limited to) the use of CDDP in combination with targeted anticancer agents such as erlotinib (a pharmacological inhibitor of the tyrosine kinase activity of EGFR), trastuzumab (an EGFR-specific antibody) and bevacizumab (a vascular endothelial growth factor-blocking antibody), a majority of these combinatorial regimens failed to improve the therapeutic profile of CDDP in randomized clinical trials. ${ }^{308-310}$

Past. Before the advent of high-content, high-throughput technologies, the elucidation of the molecular mechanisms underpinning the cytostatic/cytotoxic effects of CDDP has long been under the limelight. It was indeed tempting to accept the relatively straightforward assumptions that (i) CDDP would exert antineoplastic effects by binding one (or a few) molecular target(s), hence activating relatively simple signaling pathways, and (ii) that CDDP resistance would originate from the activation of mutually exclusive mechanisms. Starting with the early 1990s, the attention of molecular oncologists focused on the cellular factors that are responsible for the detection and repair of CDDP-elicited DNA lesions, and on the mechanisms whereby these systems transduce a lethal signal when damage is irreparable (on-target and post-target resistance). The increasingly more precise characterization of plasma membrane transporters that actively extrude various xenobiotics, including several members of the ATP-binding cassette (ABC) protein family, ${ }^{311}$ led to the hypothesis that CDDP resistance would mainly involve pre-target mechanisms. Such a hypothesis, however, was soon disconfirmed by findings from many groups indicating that the inhibition of $A B C$ transporters does not suffice to reinstate CDDP sensitivity. In the early 2000s, the role of copper transporters in the uptake and extrusion of CDDP became clear, yet the experimental modulation of these systems also failed to completely abolish the insensitivity of some cancer cells to CDDP. Thus, the redundant and multifactorial nature of CDDP resistance has been established even before the advent of high-content, high-throughput technologies.

Present. The automation of functional screenings and the introduction of high-content experimental platforms have literally revolutionized the study of several biological phenomena, including CDDP resistance. The first highcontent, high-throughput technologies (such as mRNA and $\mathrm{CGH}$ microarrays and mass spectrometry) have been available for more than a decade, but the true explosion of this area has occurred in the late 2000s, along with the commercialization of platforms such as automated fluorescence microscopes and the introduction of innovative protocols like deep sequencing. Several attempts have recently been made to harness these technologies for empirically resolving the clinical hurdle posed by CDDP resistance, with very promising results. In addition, increasingly more detailed insights into the complexity of the signal transduction pathways triggered by CDDP in cancer and normal cells have been obtained. Nonetheless, no chemosensitization strategies have yet been introduced into the clinical practice (though a few of them are currently being investigated in clinical settings).

Future. Accumulating evidence indicates that, contrarily to long-standing beliefs, the limited sensitivity of human neoplasms to CDDP may reflect not only cell-intrinsic but also cell-extrinsic alterations. ${ }^{24,25,312,313}$ On one hand, CDDP appears to be much less effective than other chemotherapeutics, including oxaliplatin (in spite of their chemical resemblance), at inducing the immunogenic demise of cancer cells. ${ }^{314,315}$ On the other hand, it has recently been shown that CDDP resistance is significantly influenced by non-transformed mesenchymal stem cells and other components of the tumor stroma, including proteins of the extracellular matrix and immunosuppressive cell populations. ${ }^{312,313,316}$ Until now, such a cell-extrinsic dimension of CDDP resistance was largely underestimated. We surmise that the application of high-content, high-throughput technologies to heterotypic experimental settings that involve not only malignant cells but also various other components of the tumor microenvironment (including endothelial, mesenchymal and immune cells) is the key for the development of efficient strategies to restore the sensitivity of multiple human neoplasms to CDDP. Along similar lines, we believe that the untargeted metabolomic profiling of CDDP-sensitive versus CDDPresistant tumor models, an approach that only recently has begun to be applied to the study of chemoresistance, ${ }^{313,317,318}$ may yield important insights into this considerable clinical impediment. 


\section{Conflict of Interest}

The authors declare no conflict of interest.

Acknowledgements. The authors are supported by the Ligue contre le Cancer (équipe labellisée); Agence National de la Recherche (ANR); Association pour la recherche sur le cancer (ARC); Associazione Italiana per la Ricerca sul Cancro (AIRC); Cancéropôle Ile-de-France; AXA Chair for Longevity Research; Institut National du Cancer (INCa); Fondation Bettencourt-Schueller; Fondation de France; Fondation pour la Recherche Médicale (FRM); the European Commission (ArtForce); the European Research Council (ERC); the LabEx Immuno-Oncology; the LabEx LERMIT; the SIRIC Stratified Oncology Cell DNA Repair and Tumor Immune Elimination (SOCRATE); the SIRIC Cancer Research and Personalized Medicine (CARPEM) and the Paris Alliance of Cancer Research Institutes (PACRI).

1. Peyrone M. Ueber die Einwirkung des Ammoniaks auf Platinchlorür. Ann Chemie Pharm 1844; 51: 1-29.

2. Burchenal JH, Kalaher K, Dew K, Lokys L. Rationale for development of platinum analogs. Cancer Treat Rep 1979; 63: 1493-1498.

3. Rosenberg B, Vancamp L, Krigas T. Inhibition of cell division in Escherichia coli by electrolysis products from a platinum electrode. Nature 1965; 205: 698-699.

4. Rosenberg B, VanCamp L, Trosko JE, Mansour VH. Platinum compounds: a new class of potent antitumour agents. Nature 1969; 222: 385-386.

5. Lebwohl D, Canetta R. Clinical development of platinum complexes in cancer therapy: an historical perspective and an update. Eur J Cancer 1998; 34: 1522-1534.

6. Kelland LR, Sharp SY, O'Neill CF, Raynaud FI, Beale PJ, Judson IR. Mini-review: discovery and development of platinum complexes designed to circumvent cisplatin resistance. J Inorg Biochem 1999; 77: 111-115.

7. Kelland $\mathrm{L}$. The resurgence of platinum-based cancer chemotherapy. Nat Rev Cancer 2007; 7: 573-584.

8. Prestayko AW, D'Aoust JC, Issell BF, Crooke ST. Cisplatin (cis-diamminedichloroplatinum II). Cancer Treat Rev 1979; 6: 17-39.

9. Galanski M. Recent developments in the field of anticancer platinum complexes Recent Pat Anticancer Drug Discov 2006; 1: 285-295.

10. Winter $C$, Albers $P$. Testicular germ cell tumors: pathogenesis, diagnosis and treatment. Nat Rev Endocrinol 2011; 7: 43-53.

11. Feldman DR, Bosl GJ, Sheinfeld J, Motzer RJ. Medical treatment of advanced testicular cancer. JAMA 2008; 299: 672-684.

12. Koberle B, Tomicic MT, Usanova S, Kaina B. Cisplatin resistance: preclinical findings and clinical implications. Biochim Biophys Acta 2010; 1806: 172-182.

13. Ozols RF. Ovarian cancer: new clinical approaches. Cancer Treat Rev 1991; 18 (Suppl A): 77-83

14. Giaccone G. Clinical perspectives on platinum resistance. Drugs 2000; 59(Suppl 4): 9-17; discussion 37-18

15. Cvitkovic E, Spaulding J, Bethune V, Martin J, Whitmore WF. Improvement of cis-dichlorodiammineplatinum (NSC 119875): therapeutic index in an animal model. Cancer 1977; 39: 1357-1361.

16. Mendoza J, Martinez J, Hernandez C, Perez-Montiel D, Castro C, Fabian-Morales E et al. Association between ERCC1 and XPA expression and polymorphisms and the response to cisplatin in testicular germ cell tumours. Br J Cancer 2013; 109: 68-75.

17. Usanova S, Piee-Staffa A, Sied U, Thomale J, Schneider A, Kaina B et al. Cisplatin sensitivity of testis tumour cells is due to deficiency in interstrand-crosslink repair and low ERCC1-XPF expression. Mol Cancer 2010; 9: 248

18. Welsh C, Day R, McGurk C, Masters JR, Wood RD, Koberle B. Reduced levels of XPA ERCC1 and XPF DNA repair proteins in testis tumor cell lines. Int J Cancer 2004; 110 352-361.

19. Cavallo F, Graziani G, Antinozzi C, Feldman DR, Houldsworth J, Bosl GJ et al. Reduced proficiency in homologous recombination underlies the high sensitivity of embryonal carcinoma testicular germ cell tumors to Cisplatin and poly (adp-ribose) polymerase inhibition. PLoS One 2012; 7: e51563.

20. Tattersall MN. Ovarian cancer chemotherapy: carboplatin as standard. Lancet 2002; 360 $500-501$

21. Mandala M, Ferretti G, Barni S. Oxaliplatin in colon cancer. N Engl J Med 2004; 351 : 1691-1692 (author reply 1691-1692).

22. Harrap KR. Preclinical studies identifying carboplatin as a viable cisplatin alternative. Cancer Treat Rev 1985; 12(Suppl A): 21-33.

23. Kidani $Y$, Inagaki $\mathrm{K}$, ligo $\mathrm{M}$, Hoshi A, Kuretani $\mathrm{K}$. Antitumor activity of 1,2-diaminocyclohexane-platinum complexes against sarcoma-180 ascites form. J Med Chem 1978; 21: 1315-1318

24. Martins I, Kepp O, Schlemmer F, Adjemian S, Tailler M, Shen S et al. Restoration of the immunogenicity of cisplatin-induced cancer cell death by endoplasmic reticulum stress. Oncogene 2011; 30: 1147-1158.

25. Tesniere A, Schlemmer F, Boige V, Kepp O, Martins I, Ghiringhelli F et al. Immunogenic death of colon cancer cells treated with oxaliplatin. Oncogene 2010; 29: 482-491.
26. Gore ME, Fryatt I, Wiltshaw E, Dawson T, Robinson BA, Calvert AH. Cisplatin/carboplatin cross-resistance in ovarian cancer. Br J Cancer 1989; 60: 767-769.

27. Hamaguchi K, Godwin AK, Yakushiji M, O'Dwyer PJ, Ozols RF, Hamilton TC. Cross-resistance to diverse drugs is associated with primary cisplatin resistance in ovarian cancer cell lines. Cancer Res 1993; 53: 5225-5232.

28. Negoro K, Yamano Y, Nakashima D, Saito K, Nakatani K, Shiiba M et al. Cross-resistance of platinum derivatives in $\mathrm{H}-1 \mathrm{R}$, a cisplatin-resistant cell line. Oncol Rep 2009; 21: 443-449.

29. Johnson SW, Laub PB, Beesley JS, Ozols RF, Hamilton TC. Increased platinum-DNA damage tolerance is associated with cisplatin resistance and cross-resistance to various chemotherapeutic agents in unrelated human ovarian cancer cell lines. Cancer Res 1997; 57: 850-856.

30. Shen DW, Akiyama S, Schoenlein P, Pastan I, Gottesman MM. Characterisation of highlevel cisplatin-resistant cell lines established from a human hepatoma cell line and human KB adenocarcinoma cells: cross-resistance and protein changes. Br J Cancer 1995; 71 : 676-683.

31. Naredi P, Heath DD, Enns RE, Howell SB. Cross-resistance between cisplatin and antimony in a human ovarian carcinoma cell line. Cancer Res 1994; 54: 6464-6468.

32. Jones M, Siracky J, Kelland LR, Harrap KR. Acquisition of platinum drug resistance and platinum cross resistance patterns in a panel of human ovarian carcinoma xenografts. Br J Cancer 1993; 67: 24-29.

33. Hill BT, Shellard SA, Hosking LK, Dempke WC, Fichtinger-Schepman AM, Tone T et al. Characterization of a cisplatin-resistant human ovarian carcinoma cell line expressing cross-resistance to 5 -fluorouracil but collateral sensitivity to methotrexate. Cancer Res 1992; 52: 3110-3118.

34. Nishio K, Sugimoto Y, Nakagawa K, Niimi S, Fujiwara Y, Bungo M et al. Cross-resistance to tumour promoters in human cancer cell lines resistant to adriamycin or cisplatin. Br J Cancer 1990; 62: 415-419.

35. Schwartz JL, Rotmensch J, Beckett MA, Jaffe DR, Toohill M, Giovanazzi SM et al. X-ray and cis-diamminedichloroplatinum(II) cross-resistance in human tumor cell lines. Cancer Res 1988; 48: 5133-5135.

36. Shen D, Pastan I, Gottesman MM. Cross-resistance to methotrexate and metals in human cisplatin-resistant cell lines results from a pleiotropic defect in accumulation of these compounds associated with reduced plasma membrane binding proteins. Cancer Res 1998; 58: 268-275.

37. Choy H. Satraplatin: an orally available platinum analog for the treatment of cancer. Expert Rev Anticancer Ther 2006; 6: 973-982.

38. Eckardt JR, Bentsion DL, Lipatov ON, Polyakov IS, Mackintosh FR, Karlin DA et al. Phase II study of picoplatin as second-line therapy for patients with small-cell lung cancer. J Clin Oncol 2009; 27: 2046-2051

39. Monneret C. Platinum anticancer drugs. From serendipity to rational design. Ann Pharm Fr 2011; 69: 286-295.

40. Sternberg CN, Petrylak DP, Sartor O, Witjes JA, Demkow T, Ferrero JM et al. Multinational, double-blind, phase III study of prednisone and either satraplatin or placebo in patients with castrate-refractory prostate cancer progressing after prior chemotherapy: the SPARC trial. J Clin Oncol 2009; 27: 5431-5438.

41. el-Khateeb M, Appleton TG, Gahan LR, Charles BG, Berners-Price SJ, Bolton AM. Reactions of cisplatin hydrolytes with methionine, cysteine, and plasma ultrafiltrate studied by a combination of HPLC and NMR techniques. J Inorg Biochem 1999; 77: 13-21.

42. Kelland LR. Preclinical perspectives on platinum resistance. Drugs 2000; 59(Suppl 4): 1-8; (discussion 37-38).

43. Eastman A. Cross-linking of glutathione to DNA by cancer chemotherapeutic platinum coordination complexes. Chem Biol Interact 1987; 61: 241-248

44. Michalke B. Platinum speciation used for elucidating activation or inhibition of Pt-containing anti-cancer drugs. J Trace Elem Med Biol 2010; 24: 69-77.

45. Timerbaev AR, Hartinger CG, Aleksenko SS, Keppler BK. Interactions of antitumor metallodrugs with serum proteins: advances in characterization using modern analytical methodology. Chem Rev 2006; 106: 2224-2248.

46. Jordan P, Carmo-Fonseca M. Molecular mechanisms involved in cisplatin cytotoxicity. Cell Mol Life Sci 2000; 57: 1229-1235.

47. Slater AF, Nobel CS, Maellaro E, Bustamante J, Kimland M, Orrenius S. Nitrone spin traps and a nitroxide antioxidant inhibit a common pathway of thymocyte apoptosis. Biochem J 1995; 306(Pt 3): 771-778.

48. Galluzzi L, Senovilla L, Vitale I, Michels J, Martins I, Kepp O et al. Molecular mechanisms of cisplatin resistance. Oncogene 2012; 31: 1869-1883.

49. Murata T, Hibasami H, Maekawa S, Tagawa T, Nakashima K. Preferential binding of cisplatin to mitochondrial DNA and suppression of ATP generation in human malignant melanoma cells. Biochem Int 1990; 20: 949-955.

50. Eastman A. The formation, isolation and characterization of DNA adducts produced by anticancer platinum complexes. Pharmacol Ther 1987; 34: 155-166.

51. Yang Z, Schumaker LM, Egorin MJ, Zuhowski EG, Guo Z, Cullen KJ. Cisplatin preferentially binds mitochondrial DNA and voltage-dependent anion channel protein in the mitochondrial membrane of head and neck squamous cell carcinoma: possible role in apoptosis. Clin Cancer Res 2006; 12: 5817-5825.

52. Bellon SF, Coleman JH, Lippard SJ. DNA unwinding produced by site-specific intrastrand cross-links of the antitumor drug cis-diamminedichloroplatinum(II). Biochemistry 1991; 30: 8026-8035. 
53. Chaney SG, Sancar A. DNA repair: enzymatic mechanisms and relevance to drug response. J Natl Cancer Inst 1996; 88: 1346-1360.

54. Furuta T, Ueda T, Aune G, Sarasin A, Kraemer KH, Pommier Y. Transcription-coupled nucleotide excision repair as a determinant of cisplatin sensitivity of human cells. Cancer Res 2002; 62: 4899-4902.

55. Kunkel TA, Erie DA. DNA mismatch repair. Annu Rev Biochem 2005; 74: 681-710.

56. Kazak L, Reyes A, Holt IJ. Minimizing the damage: repair pathways keep mitochondrial DNA intact. Nat Rev Mol Cell Biol 2012; 13: 659-671.

57. Campisi J. Aging, cellular senescence, and cancer. Annu Rev Physiol 2013; 75 685-705.

58. Lopez-Otin C, Blasco MA, Partridge L, Serrano M, Kroemer G. The hallmarks of aging Cell 2013; 153: 1194-1217.

59. Vitale I, Galluzzi L, Castedo M, Kroemer G. Mitotic catastrophe: a mechanism for avoiding genomic instability. Nat Rev Mol Cell Biol 2011; 12: 385-392.

60. Galluzzi L, Vitale I, Abrams JM, Alnemri ES, Baehrecke EH, Blagosklonny MV et al. Molecular definitions of cell death subroutines: recommendations of the Nomenclature Committee on Cell Death 2012. Cell Death Differ 2012; 19: 107-120.

61. Galluzzi L, Kepp O, Kroemer G. Mitochondria: master regulators of danger signalling. Nat Rev Mol Cell Biol 2012; 13: 780-788.

62. Deniaud A, Sharaf el dein O, Maillier E, Poncet D, Kroemer G, Lemaire C et al. Endoplasmic reticulum stress induces calcium-dependent permeability transition, mitochondrial outer membrane permeabilization and apoptosis. Oncogene 2008; 27: 285-299.

63. Tait SW, Green DR. Mitochondria and cell death: outer membrane permeabilization and beyond. Nat Rev Mol Cell Biol 2010; 11: 621-632.

64. Vandenabeele P, Galluzzi L, Vanden Berghe T, Kroemer G. Molecular mechanisms of necroptosis: an ordered cellular explosion. Nat Rev Mol Cell Biol 2010; 11: 700-714.

65. Cimprich KA, Cortez D. ATR: an essential regulator of genome integrity. Nat Rev Mol Cell Biol 2008; 9: 616-627.

66. Vousden KH, Lane DP. p53 in health and disease. Nat Rev Mol Cell Biol 2007; 8 : 275-283.

67. Sperka T, Wang J, Rudolph KL. DNA damage checkpoints in stem cells, ageing and cancer. Nat Rev Mol Cell Biol 2012; 13: 579-590.

68. Huntoon CJ, Flatten KS, Wahner Hendrickson AE, Huehls AM, Sutor SL, Kaufmann SH et al. ATR inhibition broadly sensitizes ovarian cancer cells to chemotherapy independent of BRCA status. Cancer Res 2013; 73: 3683-3691.

69. Vitale I, Galluzzi L, Vivet S, Nanty L, Dessen P, Senovilla L et al. Inhibition of Chk1 kills tetraploid tumor cells through a p53-dependent pathway. PLoS One 2007; 2 : e1337.

70. Kroemer G, Galluzzi L, Brenner C. Mitochondrial membrane permeabilization in cell death. Physiol Rev 2007; 87: 99-163.

71. Galluzzi L, Blomgren K, Kroemer G. Mitochondrial membrane permeabilization in neuronal injury. Nat Rev Neurosci 2009; 10: 481-494.

72. Sancho-Martinez SM, Prieto-Garcia L, Prieto M, Lopez-Novoa JM, Lopez-Hernandez FJ. Subcellular targets of cisplatin cytotoxicity: an integrated view. Pharmacol Ther 2012; 136: 35-55.

73. Gonzalez VM, Fuertes MA, Alonso C, Perez JM. Is cisplatin-induced cell death always produced by apoptosis? Mol Pharmacol 2001; 59: 657-663.

74. Mandic A, Hansson J, Linder S, Shoshan MC. Cisplatin induces endoplasmic reticulum stress and nucleus-independent apoptotic signaling. J Biol Chem 2003; 278: 9100-9106.

75. Berndtsson M, Hagg M, Panaretakis T, Havelka AM, Shoshan MC, Linder S. Acute apoptosis by cisplatin requires induction of reactive oxygen species but is not associated with damage to nuclear DNA. Int J Cancer 2007; 120: 175-180.

76. Obeid M, Tesniere A, Ghiringhelli F, Fimia GM, Apetoh L, Perfettini JL et al. Calreticulin exposure dictates the immunogenicity of cancer cell death. Nat Med 2007: 13: 54-61.

77. Yu F, Megyesi J, Price PM. Cytoplasmic initiation of cisplatin cytotoxicity. Am J Physiol Renal Physiol 2008; 295: F44-F52.

78. Gourdier I, Crabbe L, Andreau K, Pau B, Kroemer G. Oxaliplatin-induced mitochondria apoptotic response of colon carcinoma cells does not require nuclear DNA. Oncogene 2004; 23: 7449-7457.

79. Brenner C, Grimm S. The permeability transition pore complex in cancer cell death Oncogene 2006; 25: 4744-4756.

80. Godoy LC, Anderson CT, Chowdhury R, Trudel LJ, Wogan GN. Endogenously produced nitric oxide mitigates sensitivity of melanoma cells to cisplatin. Proc Natl Acad Sci USA 2012; 109: 20373-20378

81. Tajeddine N, Galluzzi L, Kepp O, Hangen E, Morselli E, Senovilla L et al. Hierarchical involvement of Bak, VDAC1 and Bax in cisplatin-induced cell death. Oncogene 2008; 27 : $4221-4232$.

82. Sharaf el dein O, Gallerne C, Brenner C, Lemaire C. Increased expression of VDAC sensitizes carcinoma cells to apoptosis induced by DNA cross-linking agents. Biochem Pharmacol 2012; 83: 1172-1182.

83. Vaseva AV, Marchenko ND, Ji K, Tsirka SE, Holzmann S, Moll UM. p53 opens the mitochondrial permeability transition pore to trigger necrosis. Cell 2012; 149 : 1536-1548.

84. Vandenbussche F, Vaseva I, Vissenberg K, Van Der Straeten D. Ethylene in vegetative development: a tale with a riddle. New Phytol 2012; 194: 895-909.

85. Mihara M, Erster S, Zaika A, Petrenko O, Chittenden T, Pancoska P et al. p53 has a direct apoptogenic role at the mitochondria. Mol Cell 2003; 11: 577-590.
86. Chipuk JE, Kuwana T, Bouchier-Hayes L, Droin NM, Newmeyer DD, Schuler M et al. Direct activation of Bax by p53 mediates mitochondrial membrane permeabilization and apoptosis. Science 2004; 303: 1010-1014.

87. Hodeify R, Megyesi J, Tarcsafalvi A, Safirstein RL, Price PM. Protection of cisplatin cytotoxicity by an inactive cyclin-dependent kinase. Am J Physiol Renal Physiol 2010; 299: F112-F120.

88. Yoshida M, Khokhar AR, Siddik ZH. Biochemical pharmacology of homologous alicyclic mixed amine platinum(II) complexes in sensitive and resistant tumor cell lines. Cancer Res 1994; 54: 3468-3473.

89. Ishida S, Lee J, Thiele DJ, Herskowitz I. Uptake of the anticancer drug cisplatin mediated by the copper transporter Ctr1 in yeast and mammals. Proc Natl Acad Sci USA 2002; 99 14298-14302.

90. Katano K, Kondo A, Safaei R, Holzer A, Samimi G, Mishima M et al. Acquisition of resistance to cisplatin is accompanied by changes in the cellular pharmacology of copper. Cancer Res 2002; 62: 6559-6565.

91. Holzer AK, Manorek GH, Howell SB. Contribution of the major copper influx transporter CTR1 to the cellular accumulation of cisplatin, carboplatin, and oxaliplatin. Mol Pharmacol 2006; 70: 1390-1394

92. More SS, Akil O, lanculescu AG, Geier EG, Lustig LR, Giacomini KM. Role of the copper transporter, CTR1, in platinum-induced ototoxicity. J Neurosci 2010; 30: 9500-9509.

93. Ishida S, McCormick F, Smith-McCune K, Hanahan D. Enhancing tumor-specific uptake of the anticancer drug cisplatin with a copper chelator. Cancer Cell 2010; 17 574-583

94. Zischka H, Lichtmannegger J, Schmitt S, Jagemann N, Schulz S, Wartini D et al. Liver mitochondrial membrane crosslinking and destruction in a rat model of Wilson disease. $J$ Clin Invest 2011; 121: 1508-1518.

95. Komatsu M, Sumizawa T, Mutoh M, Chen ZS, Terada K, Furukawa T et al. Coppertransporting P-type adenosine triphosphatase (ATP7B) is associated with cisplatin resistance. Cancer Res 2000; 60: 1312-1316.

96. Safaei R, Holzer AK, Katano K, Samimi G, Howell SB. The role of copper transporters in the development of resistance to Pt drugs. J Inorg Biochem 2004; 98: 1607-1613.

97. Aida T, Takebayashi Y, Shimizu T, Okamura C, Higasimoto M, Kanzaki A et al. Expression of copper-transporting P-type adenosine triphosphatase (ATP7B) as a prognostic factor in human endometrial carcinoma. Gynecol Oncol 2005; 97: 41-45.

98. Nakayama K, Kanzaki A, Ogawa K, Miyazaki K, Neamati N, Takebayashi Y. Copper-transporting P-type adenosine triphosphatase (ATP7B) as a cisplatin based chemoresistance marker in ovarian carcinoma: comparative analysis with expression of MDR1, MRP1, MRP2, LRP and BCRP. Int J Cancer 2002; 101: 488-495.

99. Nakayama K, Kanzaki A, Terada K, Mutoh M, Ogawa K, Sugiyama T et al. Prognostic value of the Cu-transporting ATPase in ovarian carcinoma patients receiving cisplatinbased chemotherapy. Clin Cancer Res 2004; 10: 2804-2811.

100. Kalayda GV, Wagner CH, Buss I, Reedijk J, Jaehde U. Altered localisation of the copper efflux transporters ATP7A and ATP7B associated with cisplatin resistance in human ovarian carcinoma cells. BMC Cancer 2008; 8: 175

101. Chen HH, Yan JJ, Chen WC, Kuo MT, Lai YH, Lai WW et al. Predictive and prognostic value of human copper transporter 1 (hCtr1) in patients with stage III non-small-cell lung cancer receiving first-line platinum-based doublet chemotherapy. Lung Cancer 2012; 75 228-234.

102. Kuo MT, Fu S, Savaraj N, Chen HH. Role of the human high-affinity copper transporter in copper homeostasis regulation and cisplatin sensitivity in cancer chemotherapy. Cancer Res 2012; 72: 4616-4621.

103. Fu S, Naing A, Fu C, Kuo MT, Kurzrock R. Overcoming platinum resistance through the use of a copper-lowering agent. Mol Cancer Ther 2012; 11: 1221-1225.

104. Liang ZD, Long Y, Tsai WB, Fu S, Kurzrock R, Gagea-Iurascu M et al. Mechanistic basis for overcoming platinum resistance using copper chelating agents. Mol Cancer Ther 2012; 11: 2483-2494.

105. Cui Y, Konig J, Buchholz JK, Spring H, Leier I, Keppler D. Drug resistance and ATPdependent conjugate transport mediated by the apical multidrug resistance protein, MRP2 permanently expressed in human and canine cells. Mol Pharmacol 1999; 55: 929-937.

106. Koike K, Kawabe T, Tanaka T, Toh S, Uchiumi T, Wada M et al. A canalicular multispecific organic anion transporter (CMOAT) antisense cDNA enhances drug sensitivity in human hepatic cancer cells. Cancer Res 1997; 57: 5475-5479.

107. Liedert B, Materna V, Schadendorf D, Thomale J, Lage H. Overexpression of cMOAT (MRP2/ABCC2) is associated with decreased formation of platinum-DNA adducts and decreased G2-arrest in melanoma cells resistant to cisplatin. J Invest Dermatol 2003; 121: $172-176$

108. Korita PV, Wakai T, Shirai Y, Matsuda Y, Sakata J, Takamura M et al. Multidrug resistance-associated protein 2 determines the efficacy of cisplatin in patients with hepatocellular carcinoma. Oncol Rep 2010; 23: 965-972.

109. Yamasaki M, Makino T, Masuzawa T, Kurokawa $Y$, Miyata $H$, Takiguchi S et al. Role of multidrug resistance protein 2 (MRP2) in chemoresistance and clinical outcome in oesophageal squamous cell carcinoma. Br J Cancer 2011; 104: 707-713.

110. Moreno-Smith M, Halder JB, Meltzer PS, Gonda TA, Mangala LS, Rupaimoole R et a. ATP11B mediates platinum resistance in ovarian cancer. J Clin Invest 2013; 123 $2119-2130$

111. Lewis $A D$, Hayes JD, Wolf $C R$. Glutathione and glutathione-dependent enzymes in ovarian adenocarcinoma cell lines derived from a patient before and after the onset of 
drug resistance: intrinsic differences and cell cycle effects. Carcinogenesis 1988: 9: 1283-1287.

112. Chen $\mathrm{HH}$, Kuo MT. Role of glutathione in the regulation of cisplatin resistance in cancer chemotherapy. Met Based Drugs 2010; 2010: Article ID: 430939.

113. Kelley SL, Basu A, Teicher BA, Hacker MP, Hamer DH, Lazo JS. Overexpression of metallothionein confers resistance to anticancer drugs. Science 1988; 241 1813-1815.

114. Kasahara K, Fujiwara Y, Nishio K, Ohmori T, Sugimoto Y, Komiya K et al. Metallothionein content correlates with the sensitivity of human small cell lung cancer cell lines to cisplatin. Cancer Res 1991; 51: 3237-3242.

115. Dabholkar M, Bostick-Bruton F, Weber C, Bohr VA, Egwuagu C, Reed E. ERCC1 and ERCC2 expression in malignant tissues from ovarian cancer patients. J Natl Cancer Inst 1992; 84: 1512-1517.

116. Metzger R, Leichman CG, Danenberg KD, Danenberg PV, Lenz HJ, Hayashi K et al. ERCC1 mRNA levels complement thymidylate synthase mRNA levels in predicting response and survival for gastric cancer patients receiving combination cisplatin and fluorouracil chemotherapy. J Clin Oncol 1998; 16: 309-316.

117. Shirota Y, Stoehlmacher J, Brabender J, Xiong YP, Uetake H, Danenberg KD et al. ERCC1 and thymidylate synthase mRNA levels predict survival for colorectal cance patients receiving combination oxaliplatin and fluorouracil chemotherapy. J Clin Oncol 2001; 19: 4298-4304

118. Olaussen KA, Dunant A, Fouret $P$, Brambilla E, Andre F, Haddad V et al. DNA repair by ERCC1 in non-small-cell lung cancer and cisplatin-based adjuvant chemotherapy. N Engl J Med 2006; 355: 983-991.

119. Handra-Luca A, Hernandez J, Mountzios G, Taranchon E, Lacau-St-Guily J, Soria JC et al. Excision repair cross complementation group 1 immunohistochemical expression predicts objective response and cancer-specific survival in patients treated by Cisplatin-based induction chemotherapy for locally advanced head and neck squamous cell carcinoma. Clin Cancer Res 2007; 13: 3855-3859.

120. Bellmunt J, Paz-Ares L, Cuello M, Cecere FL, Albiol S, Guillem V et al. Gene expression of ERCC1 as a novel prognostic marker in advanced bladder cancer patients receiving cisplatin-based chemotherapy. Ann Oncol 2007; 18: 522-528.

121. Kim MK, Cho KJ, Kwon GY, Park SI, Kim YH, Kim JH et al. Patients with ERCC1-negative locally advanced esophageal cancers may benefit from preoperative chemoradiotherapy. Clin Cancer Res 2008; 14: 4225-4231.

122. Jun HJ, Ahn MJ, Kim HS, Yi SY, Han J, Lee SK et al. ERCC1 expression as a predictive marker of squamous cell carcinoma of the head and neck treated with cisplatin-based concurrent chemoradiation. Br J Cancer 2008; 99: 167-172.

123. Olaussen KA. A new step ahead for the consideration of ERCC1 as a candidate biomarker to select NSCLC patients for the treatment of cetuximab in combination with cisplatin. Cancer Biol Ther 2009; 8: 1922-1923.

124. Friboulet L, Olaussen KA, Pignon JP, Shepherd FA, Tsao MS, Graziano S et al. ERCC1 isoform expression and DNA repair in non-small-cell lung cancer. N Engl J Med 2013; 368: $1101-1110$.

125. Vaisman A, Varchenko M, Umar A, Kunkel TA, Risinger JI, Barrett JC et al. The role of $\mathrm{hMLH} 1, \mathrm{hMSH} 3$, and hMSH6 defects in cisplatin and oxaliplatin resistance: correlation with replicative bypass of platinum-DNA adducts. Cancer Res 1998; 58 : 3579-3585.

126. Aebi S, Kurdi-Haidar B, Gordon R, Cenni B, Zheng H, Fink D et al. Loss of DNA mismatch repair in acquired resistance to cisplatin. Cancer Res 1996; 56: 3087-3090.

127. Drummond JT, Anthoney A, Brown R, Modrich P. Cisplatin and adriamycin resistance are associated with MutLalpha and mismatch repair deficiency in an ovarian tumor cell line. J Biol Chem 1996; 271: 19645-19648.

128. Fink D, Aebi $S$, Howell SB. The role of DNA mismatch repair in drug resistance. Clin Cancer Res 1998: 4: 1-6.

129. Brown R, Hirst GL, Gallagher WM, Mcllwrath AJ, Margison GP, van der Zee AG et al. hMLH1 expression and cellular responses of ovarian tumour cells to treatment with cytotoxic anticancer agents. Oncogene 1997; 15: 45-52.

130. Kamal NS, Soria JC, Mendiboure J, Planchard D, Olaussen KA, Rousseau V et al. MutS homologue 2 and the long-term benefit of adjuvant chemotherapy in lung cancer Clin Cancer Res 2010; 16: 1206-1215.

131. Bassett E, Vaisman A, Tropea KA, McCall CM, Masutani C, Hanaoka F et al. Frameshifts and deletions during in vitro translesion synthesis past Pt-DNA adducts by DNA polymerases beta and eta. DNA Repair (Amst) 2002; 1: 1003-1016.

132. Zhao Y, Biertumpfel C, Gregory MT, Hua YJ, Hanaoka F, Yang W. Structural basis of human DNA polymerase eta-mediated chemoresistance to cisplatin. Proc Natl Acad Sci USA 2012; 109: 7269-7274

133. Wittschieben JP, Reshmi SC, Gollin SM, Wood RD. Loss of DNA polymerase zeta causes chromosomal instability in mammalian cells. Cancer Res 2006; 66: 134-142.

134. Roos WP, Tsaalbi-Shtylik A, Tsaryk R, Guvercin F, de Wind N, Kaina B. The translesion polymerase Rev3L in the tolerance of alkylating anticancer drugs. Mol Pharmacol 2009, 76: 927-934.

135. Wang $\mathrm{H}$, Zhang SY, Wang S, Lu J, Wu W, Weng L et al. REV3L confers chemoresistance to cisplatin in human gliomas: the potential of its RNAi for synergistic therapy Neuro Oncol 2009; 11: 790-802.

136. Smith J, Tho LM, Xu N, Gillespie DA. The ATM-Chk2 and ATR-Chk1 pathways in DNA damage signaling and cancer. Adv Cancer Res 2010; 108: 73-112.
137. Narod SA, Foulkes WD. BRCA1 and BRCA2: 1994 and beyond. Nat Rev Cancer 2004; 4 : 665-676.

138. Venkitaraman AR. Cancer susceptibility and the functions of BRCA1 and BRCA2. Cell 2002; 108: 171-182.

139. Farmer H, McCabe N, Lord CJ, Tutt AN, Johnson DA, Richardson TB et al. Targeting the DNA repair defect in BRCA mutant cells as a therapeutic strategy. Nature 2005; 434 : 917-921.

140. Bryant HE, Schultz N, Thomas HD, Parker KM, Flower D, Lopez E et al. Specific killing of BRCA2-deficient tumours with inhibitors of poly(ADP-ribose) polymerase. Nature 2005; 434: 913-917.

141. Ratnam K, Low JA. Current development of clinical inhibitors of poly(ADP-ribose) polymerase in oncology. Clin Cancer Res 2007; 13: 1383-1388.

142. Sakai W, Swisher EM, Karlan BY, Agarwal MK, Higgins J, Friedman C et al. Secondary mutations as a mechanism of cisplatin resistance in BRCA2-mutated cancers. Nature 2008; 451: 1116-1120.

143. Edwards SL, Brough R, Lord CJ, Natrajan R, Vatcheva R, Levine DA et al. Resistance to therapy caused by intragenic deletion in BRCA2. Nature 2008; 451 : $1111-1115$

144. Gibson BA, Kraus WL. New insights into the molecular and cellular functions of poly (ADP-ribose) and PARPs. Nat Rev Mol Cell Biol 2012; 13: 411-424.

145. Michels J, Vitale I, Galluzzi L, Adam J, Olaussen KA, Kepp $O$ et al. Cisplatin resistance associated with PARP hyperactivation. Cancer Res 2013; 73: 2271-2280.

146. Michels J, Vitale I, Senovilla L, Enot DP, Garcia P, Lissa D et al. Synergistic interaction between cisplatin and PARP inhibitors in non-small cell lung cancer. Cell Cycle 2013; 12: 877-883.

147. Donawho CK, Luo Y, Luo Y, Penning TD, Bauch JL, Bouska JJ et al. ABT-888, an orally active poly(ADP-ribose) polymerase inhibitor that potentiates DNA-damaging agents in preclinical tumor models. Clin Cancer Res 2007; 13: 2728-2737.

148. Evers B, Drost R, Schut E, de Bruin M, van der Burg E, Derksen PW et al. Selective inhibition of BRCA2-deficient mammary tumor cell growth by AZD2281 and cisplatin. Clin Cancer Res 2008; 14: 3916-3925.

149. Karasawa T, Sibrian-Vazquez M, Strongin RM, Steyger PS. Identification of cisplatinbinding proteins using agarose conjugates of platinum compounds. PLoS One 2013; 8: e66220.

150. Yao Z, Jones AW, Fassone E, Sweeney MG, Lebiedzinska M, Suski JM et al. PGC-1beta mediates adaptive chemoresistance associated with mitochondrial DNA mutations. Oncogene 2013; 32: 2592-2600.

151. Mizutani S, Miyato Y, Shidara Y, Asoh S, Tokunaga A, Tajiri T et al. Mutations in the mitochondrial genome confer resistance of cancer cells to anticancer drugs. Cancer Sci 2009; 100: 1680-1687

152. Jones AW, Yao Z, Vicencio JM, Karkucinska-Wieckowska A, Szabadkai G. PGC-1 family coactivators and cell fate: roles in cancer, neurodegeneration, cardiovascular disease and retrograde mitochondria-nucleus signalling. Mitochondrion 2012; 12: 86-99.

153. Abu-Hamad S, Sivan S, Shoshan-Barmatz V. The expression level of the voltagedependent anion channel controls life and death of the cell. Proc Natl Acad Sci USA 2006; 103: $5787-5792$.

154. Siddik ZH. Cisplatin: mode of cytotoxic action and molecular basis of resistance. Oncogene 2003; 22: 7265-7279.

155. Hanahan D, Weinberg RA. Hallmarks of cancer: the next generation. Cell 2011; 144: 646-674.

156. Hanahan D, Weinberg RA. The hallmarks of cancer. Cell 2000; 100: 57-70.

157. Negrini S, Gorgoulis VG, Halazonetis TD. Genomic instability-an evolving hallmark of cancer. Nat Rev Mol Cell Biol 2010; 11: 220-228.

158. Vitale I, Galluzzi L, Senovilla L, Criollo A, Jemaa M, Castedo M et al. Illicit survival of cancer cells during polyploidization and depolyploidization. Cell Death Differ 2011; 18 . 1403-1413

159. Chao CC, Huang SL, Huang HM, Lin-Chao S. Cross-resistance to UV radiation of a cisplatin-resistant human cell line: overexpression of cellular factors that recognize UV-modified DNA. Mol Cell Biol 1991; 11: 2075-2080.

160. Okouoyo S, Herzer K, Ucur E, Mattern J, Krammer PH, Debatin KM et al. Rescue of death receptor and mitochondrial apoptosis signaling in resistant human NSCLC in vivo. Int J Cancer 2004; 108: 580-587.

161. Kroemer G, Marino G, Levine B. Autophagy and the integrated stress response. Mol Cell 2010; 40: 280-293.

162. Vicencio JM, Galluzzi L, Tajeddine N, Ortiz C, Criollo A, Tasdemir E et al. Senescence, apoptosis or autophagy? When a damaged cell must decide its path-a mini-review. Gerontology 2008; 54: 92-99

163. Mandic A, Viktorsson K, Varsanyi M, Hansson J, Linder S, Shoshan M. BAK, BAX and p53 proteins in the apoptotic response to cisplatin. Nat Genet 2001; 27: 86.

164. Kim JS, Lee JH, Jeong WW, Choi DH, Cha HJ, Kim do H et al. Reactive oxygen speciesdependent EndoG release mediates cisplatin-induced caspase-independent apoptosis in human head and neck squamous carcinoma cells. Int J Cancer 2008; 122: 672-680.

165. Galluzzi L, Kepp O, Trojel-Hansen C, Kroemer G. Mitochondrial control of cellular life, stress, and death. Circ Res 2012; 111: 1198-1207.

166. Branch P, Masson M, Aquilina G, Bignami M, Karran P. Spontaneous development of drug resistance: mismatch repair and p53 defects in resistance to cisplatin in human tumor cells. Oncogene 2000; 19: 3138-3145. 
167. O'Connor PM, Jackman J, Bae I, Myers TG, Fan S, Mutoh M et al. Characterization of the p53 tumor suppressor pathway in cell lines of the National Cancer Institute anticancer drug screen and correlations with the growth-inhibitory potency of 123 anticancer agents. Cancer Res 1997; 57: 4285-4300.

168. Hengstler JG, Pilch H, Schmidt M, Dahlenburg H, Sagemuller J, Schiffer I et al. Metallothionein expression in ovarian cancer in relation to histopathological parameters and molecular markers of prognosis. Int J Cancer 2001; 95: 121-127.

169. Gadducci A, Cosio S, Muraca S, Genazzani AR. Molecular mechanisms of apoptosis and chemosensitivity to platinum and paclitaxel in ovarian cancer: biological data and clinical implications. Eur J Gynaecol Oncol 2002; 23: 390-396.

170. Goloudina AR, Tanoue K, Hammann A, Fourmaux E, Le Guezennec X, Bulavin DV et al. Wip1 promotes RUNX2-dependent apoptosis in p53-negative tumors and protects normal tissues during treatment with anticancer agents. Proc Natl Acad Sci USA 2012 109: E68-E75.

171. Brozovic A, Fritz G, Christmann M, Zisowsky J, Jaehde U, Osmak M et al. Long-term activation of SAPK/JNK, p38 kinase and fas-L expression by cisplatin is attenuated in human carcinoma cells that acquired drug resistance. Int J Cancer 2004; 112: 974-985.

172. Mansouri A, Ridgway LD, Korapati AL, Zhang $Q$, Tian L, Wang $Y$ et al. Sustained activation of JNK/p38 MAPK pathways in response to cisplatin leads to Fas ligand induction and cell death in ovarian carcinoma cells. J Biol Chem 2003; 278 19245-19256.

173. Sakamoto M, Kondo A, Kawasaki K, Goto T, Sakamoto H, Miyake K et al. Analysis of gene expression profiles associated with cisplatin resistance in human ovarian cancer cell lines and tissues using cDNA microarray. Hum Cell 2001; 14: 305-315.

174. de La Motte Rouge T, Galluzzi L, Olaussen KA, Zermati Y, Tasdemir E, Robert T et al. A novel epidermal growth factor receptor inhibitor promotes apoptosis in non-small cell lung cancer cells resistant to erlotinib. Cancer Res 2007; 67: 6253-6262.

175. Han JY, Hong EK, Choi BG, Park JN, Kim KW, Kang JH et al. Death receptor 5 and Bcl-2 protein expression as predictors of tumor response to gemcitabine and cisplatin in patients with advanced non-small-cell lung cancer. Med Oncol 2003; 20: 355-362.

176. Michaud WA, Nichols AC, Mroz EA, Faquin WC, Clark JR, Begum S et al. Bcl-2 blocks cisplatin-induced apoptosis and predicts poor outcome following chemoradiation treatment in advanced oropharyngeal squamous cell carcinoma. Clin Cancer Res 2009; 15: 1645-1654.

177. Williams J, Lucas PC, Griffith KA, Choi M, Fogoros S, Hu YY et al. Expression of Bcl-xL in ovarian carcinoma is associated with chemoresistance and recurrent disease. Gynecol Oncol 2005; 96: 287-295.

178. Erovic BM, Pelzmann M, Grasl M, Pammer J, Kornek G, Brannath W et al. Mcl-1, vascular endothelial growth factor-R2, and 14-3-3sigma expression might predict primary response against radiotherapy and chemotherapy in patients with locally advanced squamous cell carcinomas of the head and neck. Clin Cancer Res 2005; 11: 8632-8636.

179. Nakamura M, Tsuji N, Asanuma K, Kobayashi D, Yagihashi A, Hirata K et al. Survivin as a predictor of cis-diamminedichloroplatinum sensitivity in gastric cancer patients. Cancer Sci 2004; 95: 44-51.

180. Karczmarek-Borowska B, Filip A, Wojcierowski J, Smolen A, Pilecka I, Jablonka A. Survivin antiapoptotic gene expression as a prognostic factor in non-small cell lung cancer: in situ hybridization study. Folia Histochem Cytobiol 2005; 43: 237-242.

181. Kato J, Kuwabara Y, Mitani M, Shinoda N, Sato A, Toyama T et al. Expression of survivin in esophageal cancer: correlation with the prognosis and response to chemotherapy. Int $J$ Cancer 2001; 95: 92-95.

182. Ikeguchi M, Kaibara N. Changes in survivin messenger RNA level during cisplatin treatment in gastric cancer. Int J Mol Med 2001; 8: 661-666.

183. Keating J, Tsoli M, Hallahan AR, Ingram WJ, Haber M, Ziegler DS. Targeting the inhibitor of apoptosis proteins as a novel therapeutic strategy in medulloblastoma. Mol Cancer Ther 2012; 11: 2654-2663.

184. Wilson WH, O'Connor OA, Czuczman MS, LaCasce AS, Gerecitano JF, Leonard JP et al. Navitoclax, a targeted high-affinity inhibitor of BCL-2, in lymphoid malignancies: a phase 1 dose-escalation study of safety, pharmacokinetics, pharmacodynamics, and antitumour activity. Lancet Oncol 2010; 11: 1149-1159.

185. Rudin CM, Hann CL, Garon EB, Ribeiro de Oliveira M, Bonomi PD, Camidge DR et al. Phase II study of single-agent navitoclax (ABT-263) and biomarker correlates in patients with relapsed small cell lung cancer. Clin Cancer Res 2012; 18: 3163-3169.

186. Giaccone G, Zatloukal P, Roubec J, Floor K, Musil J, Kuta M et al. Multicenter phase II trial of YM155, a small-molecule suppressor of survivin, in patients with advanced, refractory, non-small-cell lung cancer. J Clin Oncol 2009; 27: 4481-4486.

187. Tolcher AW, Mita A, Lewis LD, Garrett CR, Till E, Daud Al et al. Phase I and pharmacokinetic study of YM155, a small-molecule inhibitor of survivin. J Clin Oncol 2008 26: 5198-5203.

188. Tanioka M, Nokihara H, Yamamoto N, Yamada Y, Yamada K, Goto Y et al. Phase I study of LY2181308, an antisense oligonucleotide against survivin, in patients with advanced solid tumors. Cancer Chemother Pharmacol 2011; 68: 505-511.

189. Slamon DJ, Godolphin W, Jones LA, Holt JA, Wong SG, Keith DE et al. Studies of the HER-2/neu proto-oncogene in human breast and ovarian cancer. Science 1989; 244 707-712.

190. Hengstler JG, Lange J, Kett A, Dornhofer N, Meinert R, Arand M et al. Contribution of c-erbB-2 and topoisomerase Ilalpha to chemoresistance in ovarian cancer. Cancer Res 1999; 59: 3206-3214
191. Fijolek J, Wiatr E, Rowinska-Zakrzewska E, Giedronowicz D, Langfort R, Chabowski M et al. p53 and HER2/neu expression in relation to chemotherapy response in patients with non-small cell lung cancer. Int J Biol Markers 2006; 21: 81-87.

192. Zhou BP, Liao Y, Xia W, Spohn B, Lee MH, Hung MC. Cytoplasmic localization of p21Cip1/WAF1 by Akt-induced phosphorylation in HER-2/neu-overexpressing cells. Nat Cell Biol 2001; 3: 245-252.

193. Deng X, Ewton DZ, Friedman E. Mirk/Dyrk1B maintains the viability of quiescent pancreatic cancer cells by reducing levels of reactive oxygen species. Cancer Res 2009; 69: 3317-3324.

194. Shen DW, Gottesman MM. RAB8 enhances TMEM205-mediated cisplatin resistance. Pharm Res 2012; 29: 643-650

195. Shen DW, Ma J, Okabe M, Zhang G, Xia D, Gottesman MM. Elevated expression of TMEM205, a hypothetical membrane protein, is associated with cisplatin resistance. J Cell Physiol 2010; 225: 822-828.

196. Messina S, Leonetti C, De Gregorio G, Affatigato V, Ragona G, Frati L et al. Ras inhibition amplifies cisplatin sensitivity of human glioblastoma. Biochem Biophys Res Commun 2004; 320: 493-500.

197. Yu H, Su J, Xu Y, Kang J, Li H, Zhang L et al. p62/SQSTM1 involved in cisplatin resistance in human ovarian cancer cells by clearing ubiquitinated proteins. Eur $\mathrm{J}$ Cance 2011; 47: 1585-1594.

198. Ren JH, He WS, Nong L, Zhu QY, Hu K, Zhang RG et al. Acquired cisplatin resistance in human lung adenocarcinoma cells is associated with enhanced autophagy. Cancer Biother Radiopharm 2010; 25: 75-80.

199. Zhang Y, Shen X. Heat shock protein 27 protects $L 929$ cells from cisplatin-induced apoptosis by enhancing Akt activation and abating suppression of thioredoxin reductase activity. Clin Cancer Res 2007; 13: 2855-2864.

200. Yamamoto K, Okamoto A, Isonishi S, Ochiai K, Ohtake Y. Heat shock protein 27 was up-regulated in cisplatin resistant human ovarian tumor cell line and associated with the cisplatin resistance. Cancer Lett 2001; 168: 173-181.

201. Ren A, Yan G, You B, Sun J. Down-regulation of mammalian sterile 20-like kinase 1 by heat shock protein 70 mediates cisplatin resistance in prostate cancer cells. Cancer Res 2008; 68: 2266-2274.

202. Miyazaki T, Kato H, Faried A, Sohda M, Nakajima M, Fukai $Y$ et al. Predictors of response to chemo-radiotherapy and radiotherapy for esophageal squamous cell carcinoma Anticancer Res 2005; 25: 2749-2755.

203. Shen DW, Pouliot LM, Hall MD, Gottesman MM. Cisplatin resistance: a cellular self-defense mechanism resulting from multiple epigenetic and genetic changes. Pharmacol Rev 2012; 64: 706-721.

204. He JC, Chuang PY, Ma'ayan A, lyengar R. Systems biology of kidney diseases. Kidney Int 2012; 81: 22-39.

205. Lee NH, Saeed Al. Microarrays: an overview. Methods Mol Biol 2007; 353: 265-300.

206. Nilsson T, Mann M, Aebersold R, Yates JR 3rd, Bairoch A, Bergeron JJ. Mass spectrometry in high-throughput proteomics: ready for the big time. Nat Methods 2010; 7 681-685

207. Monetti M, Nagaraj N, Sharma K, Mann M. Large-scale phosphosite quantification in tissues by a spike-in SILAC method. Nat Methods 2011; 8: 655-658.

208. Johnson SA, Hunter T. Kinomics: methods for deciphering the kinome. Nat Methods 2005; 2: 17-25.

209. Mertins P, Qiao JW, Patel J, Udeshi ND, Clauser KR, Mani DR et al. Integrated proteomic analysis of post-translational modifications by serial enrichment. Nat Methods 2013; 10 634-637.

210. Berger MF, Lawrence MS, Demichelis F, Drier Y, Cibulskis K, Sivachenko AY et al The genomic complexity of primary human prostate cancer. Nature 2011; 470 214-220.

211. Ley TJ, Mardis ER, Ding L, Fulton B, McLellan MD, Chen $\mathrm{K}$ et al. DNA sequencing of a cytogenetically normal acute myeloid leukaemia genome. Nature 2008; 456 66-72.

212. Pleasance ED, Cheetham RK, Stephens PJ, McBride DJ, Humphray SJ, Greenman CD et al. A comprehensive catalogue of somatic mutations from a human cancer genome. Nature 2010; 463: 191-196.

213. Pleasance ED, Stephens PJ, O'Meara S, McBride DJ, Meynert A, Jones D et al A small-cell lung cancer genome with complex signatures of tobacco exposure. Nature 2010; 463: 184-190.

214. Shah SP, Morin RD, Khattra J, Prentice L, Pugh T, Burleigh A et al. Mutational evolution in a lobular breast tumour profiled at single nucleotide resolution. Nature 2009; 461 809-813.

215. Murtaza M, Dawson SJ, Tsui DW, Gale D, Forshew T, Piskorz AM et al. Non-invasive analysis of acquired resistance to cancer therapy by sequencing of plasma DNA. Nature 2013; 497: 108-112.

216. Cui L, Fu J, Pang JC, Qiu ZK, Liu XM, Chen FR et al. Overexpression of IL-7 enhances cisplatin resistance in glioma. Cancer Biol Ther 2012; 13: 496-503.

217. Lee JH, Miele ME, Hicks DJ, Phillips KK, Trent JM, Weissman BE et al. KiSS-1, a novel human malignant melanoma metastasis-suppressor gene. J Natl Cancer Inst 1996; 88: $1731-1737$

218. Jiffar T, Yilmaz T, Lee J, Hanna E, El-Naggar A, Yu D et al. KiSS1 mediates platinum sensitivity and metastasis suppression in head and neck squamous cell carcinoma. Oncogene 2011; 30: 3163-3173. 
219. Yu W, Jin C, Lou X, Han X, Li L, He Y et al. Global analysis of DNA methylation by Methyl-Capture sequencing reveals epigenetic control of cisplatin resistance in ovarian cancer cell. PLoS One 2011; 6: e29450.

220. Zeller C, Dai W, Steele NL, Siddiq A, Walley AJ, Wilhelm-Benartzi CS et al. Candidate DNA methylation drivers of acquired cisplatin resistance in ovarian cancer identified by methylome and expression profiling. Oncogene 2012; 31: 4567-4576.

221. Ivanova T, Zouridis H, Wu Y, Cheng LL, Tan IB, Gopalakrishnan V et al. Integrated epigenomics identifies BMP4 as a modulator of cisplatin sensitivity in gastric cancer Gut 2013; 62: 22-33.

222. Chon HS, Marchion DC, Xiong Y, Chen N, Bicaku E, Stickles XB et al. The BCL2 antagonist of cell death pathway influences endometrial cancer cell sensitivity to cisplatin. Gynecol Oncol 2012; 124: 119-124.

223. Yu HM, Wang TC. Mechanism of cisplatin resistance in human urothelial carcinoma cells Food Chem Toxicol 2012; 50: 1226-1237.

224. Lai TC, Chow KC, Fang HY, Cho HC, Chen CY, Lin TY et al. Expression of xeroderma pigmentosum complementation group $\mathrm{C}$ protein predicts cisplatin resistance in lung adenocarcinoma patients. Oncol Rep 2011; 25: 1243-1251.

225. Koch M, Krieger ML, Stolting D, Brenner N, Beier M, Jaehde $U$ et al. Overcoming chemotherapy resistance of ovarian cancer cells by liposomal cisplatin: molecula mechanisms unveiled by gene expression profiling. Biochem Pharmacol 2013; 85 : 1077-1090.

226. Marchion DC, Cottrill HM, Xiong Y, Chen N, Bicaku E, Fulp WJ et al. BAD phosphorylation determines ovarian cancer chemosensitivity and patient survival. Clin Cancer Res 2011 17: 6356-6366.

227. Kim HK, Choi IJ, Kim CG, Kim HS, Oshima A, Michalowski A et al. A gene expression signature of acquired chemoresistance to cisplatin and fluorouracil combination chemotherapy in gastric cancer patients. PLoS One 2011; 6: e16694.

228. Barlin JN, Jelinic P, Olvera N, Bogomolniy F, Bisogna M, Dao F et al. Validated gene targets associated with curatively treated advanced serous ovarian carcinoma. Gynecol Oncol 2013; 128: 512-517.

229. Marchini S, Fruscio R, Clivio L, Beltrame L, Porcu L, Nerini IF et al. Resistance to platinum-based chemotherapy is associated with epithelial to mesenchymal transition in epithelial ovarian cancer. Eur J Cancer 2013; 49: 520-530.

230. Tomkiewicz C, Hans S, Mucchielli MH, Agier N, Delacroix H, Marisa L et al. A head and neck cancer tumor response-specific gene signature for cisplatin, 5 -fluorouracil induction chemotherapy fails with added taxanes. PLOS One 2012; 7: e47170.

231. Galluzzi L, Vitale I, Senovilla L, Eisenberg T, Carmona-Gutierrez D, Vacchelli E et al. Independent transcriptional reprogramming and apoptosis induction by cisplatin Cell Cycle 2012; 11: 3472-3480.

232. Galluzzi L, Morselli E, Vitale I, Kepp O, Senovilla L, Criollo A et al. miR-181a and miR-630 regulate cisplatin-induced cancer cell death. Cancer Res 2010; 70 1793-1803.

233. Guo Y, Yan K, Fang J, Qu Q, Zhou M, Chen F. Let-7b expression determines response to chemotherapy through the regulation of cyclin D1 in glioblastoma. J Exp Clin Cancer Res 2013; 32: 41.

234. Sun L, Yao Y, Liu B, Lin Z, Lin L, Yang M et al. MiR-200b and miR-15b regulate chemotherapy-induced epithelial-mesenchymal transition in human tongue cancer cells by targeting BMl1. Oncogene 2012; 31: 432-445.

235. Zhou L, Qiu T, Xu J, Wang T, Wang J, Zhou X et al. miR-135a/b modulate cisplatin resistance of human lung cancer cell line by targeting MCL1. Pathol Oncol Res 2013; 19 : 677-683.

236. Zhu W, Zhu D, Lu S, Wang T, Wang J, Jiang B et al. miR-497 modulates multidrug resistance of human cancer cell lines by targeting BCL2. Med Oncol 2012; 29 384-391.

237. Wang Q, Zhong M, Liu W, Li J, Huang J, Zheng L. Alterations of microRNAs in cisplatinresistant human non-small cell lung cancer cells (A549/DDP). Exp Lung Res 2011; 37 427-434

238. Yang Y, Li H, Hou S, Hu B, Liu J, Wang J. The noncoding RNA expression profile and the effect of IncRNA AK126698 on cisplatin resistance in non-small-cell lung cancer cells PLoS One 2013; 8: e65309.

239. Zhuo L, Liu J, Wang B, Gao M, Huang A. Differential miRNA expression profiles in hepatocellular carcinoma cells and drug-resistant sublines. Oncol Rep 2013; 29 : $555-562$

240. Yang L, Li N, Wang H, Jia X, Wang X, Luo J. Altered microRNA expression in cisplatin-resistant ovarian cancer cells and upregulation of miR-130a associated with MDR1/P-glycoprotein-mediated drug resistance. Oncol Rep 2012; 28: 592-600.

241. Fu X, Tian J, Zhang L, Chen Y, Hao Q. Involvement of microRNA-93, a new regulator of PTEN/Akt signaling pathway, in regulation of chemotherapeutic drug cisplatin chemosensitivity in ovarian cancer cells. FEBS Lett 2012; 586: 1279-1286.

242. Kim CH, Kim HK, Rettig RL, Kim J, Lee ET, Aprelikova $\mathrm{O}$ et al. miRNA signature associated with outcome of gastric cancer patients following chemotherapy. BMC Med Genomics 2011; 4: 79

243. Ko MA, Zehong G, Virtanen C, Guindi M, Waddell TK, Keshavjee S et al. MicroRNA expression profiling of esophageal cancer before and after induction chemoradiotherapy. Ann Thorac Surg 2012; 94: 1094-1102.

244. Scott GK, Mattie MD, Berger CE, Benz SC, Benz CC. Rapid alteration of microRNA levels by histone deacetylase inhibition. Cancer Res 2006; 66: 1277-1281.
245. Zhu J, Jiang Z, Gao F, Hu X, Zhou L, Chen J et al. A systematic analysis on DNA methylation and the expression of both mRNA and microRNA in bladder cancer. PLoS One 2011; 6: e28223.

246. Bangert A, Hacker S, Cristofanon S, Debatin KM, Fulda S. Chemosensitization of glioblastoma cells by the histone deacetylase inhibitor MS275. Anticancer Drugs 2011; 22: 494-499.

247. Rikiishi H, Shinohara F, Sato T, Sato Y, Suzuki M, Echigo S. Chemosensitization of oral squamous cell carcinoma cells to cisplatin by histone deacetylase inhibitor, suberoylanilide hydroxamic acid. Int J Oncol 2007; 30: 1181-1188.

248. Wang F, Liu M, Li X, Tang H. MiR-214 reduces cell survival and enhances cisplatininduced cytotoxicity via down-regulation of $\mathrm{Bcl} 2 \mathrm{l} 2$ in cervical cancer cells. FEBS Lett 2013; 587: 488-495.

249. Eriksson I, Joosten M, Roberg K, Ollinger K. The histone deacetylase inhibitor trichostatin A reduces lysosomal pH and enhances cisplatin-induced apoptosis. Exp Cell Res 2013; 319: 12-20.

250. Ozaki K, Kishikawa F, Tanaka M, Sakamoto T, Tanimura S, Kohno M. Histone deacetylase inhibitors enhance the chemosensitivity of tumor cells with cross-resistance to a wide range of DNA-damaging drugs. Cancer Sci 2008; 99: 376-384.

251. Steele N, Finn $P$, Brown R, Plumb JA. Combined inhibition of DNA methylation and histone acetylation enhances gene re-expression and drug sensitivity in vivo. $\mathrm{Br} \mathrm{J}$ Cancer 2009; 100: 758-763

252. Quu YY, Mirkin BL, Dwivedi RS. Inhibition of DNA methyltransferase reverses cisplatin induced drug resistance in murine neuroblastoma cells. Cancer Detect Prev 2005; 29: 456-463.

253. Chavez JD, Hoopmann MR, Weisbrod CR, Takara K, Bruce JE. Quantitative proteomic and interaction network analysis of cisplatin resistance in HeLa cells. PLoS One 2011; 6 : e19892.

254. Zeng HZ, Qu YQ, Zhang WJ, Xiu B, Deng AM, Liang AB. Proteomic analysis identified DJ-1 as a cisplatin resistant marker in non-small cell lung cancer. Int J Mol Sci 2011; 12: 3489-3499.

255. Roesch A, Vultur A, Bogeski I, Wang H, Zimmermann KM, Speicher D et al. Overcoming intrinsic multidrug resistance in melanoma by blocking the mitochondrial respiratory chain of slow-cycling JARID1B(high) cells. Cancer Cell 2013; 23: 811-825.

256. Aichler M, Elsner M, Ludyga N, Feuchtinger A, Zangen V, Maier SK et al. Clinical response to chemotherapy in oesophageal adenocarcinoma patients is linked to defects in mitochondria. J Pathol 2013; 230: 410-419.

257. Vasko R, Mueller GA, von Jaschke AK, Asif AR, Dihazi H. Impact of cisplatin administration on protein expression levels in renal cell carcinoma: a proteomic analysis. Eur J Pharmacol 2011; 670: 50-57.

258. Chappell NP, Teng PN, Hood BL, Wang G, Darcy KM, Hamilton CA et al. Mitochondrial proteomic analysis of cisplatin resistance in ovarian cancer. J Proteome Res 2012; 11: 4605-4614.

259. Zhang G, Sun L, Lu X, Chen Z, Duerksen-Hughes PJ, Hu H et al. Cisplatin treatment leads to changes in nuclear protein and microRNA expression. Mutat Res 2012; 746: 66-77.

260. Shetty V, Nickens Z, Testa J, Hafner J, Sinnathamby G, Philip R. Quantitative immunoproteomics analysis reveals novel MHC class I presented peptides in cisplatin-resistant ovarian cancer cells. J Proteomics 2012; 75: 3270-3290.

261. Garand C, Guay D, Sereduk C, Chow D, Tsofack SP, Langlois M et al. An integrative approach to identify $\mathrm{YB}-1$-interacting proteins required for cisplatin resistance in MCF7 and MDA-MB-231 breast cancer cells. Cancer Sci 2011; 102: 1410-1417.

262. Huang W, Ding X, Li B, Fan M, Zhou T, Sun $\mathrm{H}$ et al. Serum biomarkers analyzed by LC-MS/MS as predictors for short outcome of non-small cell lung cancer patients treated with chemoradiotherapy. Neoplasma 2013; 60: 11-18.

263. Han M, Dai J, Zhang Y, Lin Q, Jiang M, Xu X et al Support vector machines coupled with proteomics approaches for detecting biomarkers predicting chemotherapy resistance in small cell lung cancer. Oncol Rep 2012; 28: 2233-2238.

264. Zitvogel L, Galluzzi L, Smyth MJ, Kroemer G. Mechanism of action of conventional and targeted anticancer therapies: reinstating immunosurveillance. Immunity 2013; 39: 74-88.

265. Galluzzi L, Senovilla L, Zitvogel L, Kroemer G. The secret ally: immunostimulation by anticancer drugs. Nat Rev Drug Discov 2012; 11: 215-233.

266. Kittler R, Putz G, Pelletier L, Poser I, Heninger AK, Drechsel D et al. An endoribonuclease-prepared siRNA screen in human cells identifies genes essential for cell division. Nature 2004; 432: 1036-1040.

267. Sachse C, Echeverri CJ. Oncology studies using siRNA libraries: the dawn of RNAi-based genomics. Oncogene 2004; 23: 8384-8391.

268. Schimmer AD, Welsh K, Pinilla C, Wang Z, Krajewska M, Bonneau MJ et al. Small-molecule antagonists of apoptosis suppressor XIAP exhibit broad antitumor activity. Cancer Cell 2004; 5: 25-35.

269. Newman MJ, Rodarte JC, Benbatoul KD, Romano SJ, Zhang C, Krane S et al. Discovery and characterization of OC144-093, a novel inhibitor of P-glycoprotein-mediated multidrug resistance. Cancer Res 2000; 60: 2964-2972.

270. Alcala S, Klee M, Fernandez J, Fleischer A, Pimentel-Muinos FX. A high-throughput screening for mammalian cell death effectors identifies the mitochondrial phosphate carrier as a regulator of cytochrome c release. Oncogene 2008; 27: 44-54.

271. Sun C, Newbatt Y, Douglas L, Workman P, Aherne W, Linardopoulos S. High-throughput screening assay for identification of small molecule inhibitors of Aurora2/STK15 kinase. J Biomol Screen 2004; 9: 391-397.

272. Galluzzi L, Vitale I, Senovilla L, Olaussen KA, Pinna G, Eisenberg T et al. Prognostic impact of vitamin B6 metabolism in lung cancer. Cell Rep 2012; 2: 257-269. 
273. Galluzzi L, Marsili S, Vitale I, Senovilla L, Michels J, Garcia P et al. Vitamin B6 metabolism influences the intracellular accumulation of cisplatin. Cell Cycle 2013; 12: 417-421.

274. Jacquemont C, Simon JA, D'Andrea AD, Taniguchi T. Non-specific chemical inhibition of the Fanconi anemia pathway sensitizes cancer cells to cisplatin. Mol Cancer 2012; 11: 26.

275. Chen J, Dexheimer TS, Ai Y, Liang Q, Villamil MA, Inglese J et al. Selective and cellactive inhibitors of the USP1/ UAF1 deubiquitinase complex reverse cisplatin resistance in non-small cell lung cancer cells. Chem Biol 2011; 18: 1390-1400.

276. Salm F, Cwiek P, Ghosal A, Lucia Buccarello A, Largey F, Wotzkow C et al. RNA interference screening identifies a novel role for autocrine fibroblast growth factor signaling in neuroblastoma chemoresistance. Oncogene 2013; 32: 3944-3953.

277. Ho H, Aruri J, Kapadia R, Mehr H, White MA, Ganesan AK. RhoJ regulates melanoma chemoresistance by suppressing pathways that sense DNA damage. Cancer Res 2012; 72: $5516-5528$.

278. Li G, Alexander H, Schneider N, Alexander S. Molecular basis for resistance to the anticancer drug cisplatin in Dictyostelium. Microbiology 2000; 146(Pt 9): 2219-2227.

279. Liao C, Hu B, Arno MJ, Panaretou B. Genomic screening in vivo reveals the role played by vacuolar $\mathrm{H}+$ ATPase and cytosolic acidification in sensitivity to DNA-damaging agents such as cisplatin. Mol Pharmacol 2007; 71: 416-425.

280. Gatti L, Hoe KL, Hayles J, Righetti SC, Carenini N, Bo LD et al. Ubiquitin-proteasome genes as targets for modulation of cisplatin sensitivity in fission yeast. BMC Genomics 2011; 12: 44.

281. Sletta H, Klinkenberg G, Winnberg A, Kvitvang HF, Nilsen MB, Krokan HE et al. A new high resolution screening method for study of phenotype stress responses of Saccharomyces cerevisae mutants. J Microbiol Methods 2011; 87: 363-367.

282. Galluzzi L, Vacchelli E, Michels J, Garcia P, Kepp O, Senovilla L et al. Effects of vitamin B6 metabolism on oncogenesis, tumor progression and therapeutic responses. Oncogene 2013; 32: 4995-5004

283. Galluzzi L, Goubar A, Olaussen KA, Vitale I, Senovilla L, Michels J et al. Prognostic value of LIPC in non-small cell lung carcinoma. Cell Cycle 2013; 12: 647-654.

284. Guerreiro AS, Fattet S, Kulesza DW, Atamer A, Elsing AN, Shalaby $T$ et al. A sensitized RNA interference screen identifies a novel role for the PI3K p110gamma isoform in medulloblastoma cell proliferation and chemoresistance. Mol Cancer Res 2011; 9: 925-935.

285. Pouliot LM, Chen YC, Bai J, Guha R, Martin SE, Gottesman MM et al. Cisplatin sensitivity mediated by WEE 1 and CHK1 is mediated by miR-155 and the miR-15 family. Cancer Res 2012; 72: 5945-5955.

286. Wong SW, Tiong KH, Kong WY, Yue YC, Chua CH, Lim JY et al. Rapamycin synergizes cisplatin sensitivity in basal-like breast cancer cells through up-regulation of p73. Breast Cancer Res Treat 2011; 128: 301-313.

287. Garnett MJ, Edelman EJ, Heidorn SJ, Greenman CD, Dastur A, Lau KW et al. Systematic identification of genomic markers of drug sensitivity in cancer cells. Nature 2012; 483 : 570-575.

288. Krajinovic M, Costea I, Chiasson S. Polymorphism of the thymidylate synthase gene and outcome of acute lymphoblastic leukaemia. Lancet 2002; 359: 1033-1034.

289. Shahbazi M, Pravica V, Nasreen N, Fakhoury H, Fryer AA, Strange RC et al. Association between functional polymorphism in EGF gene and malignant melanoma. Lancet 2002; 359: 397-401.

290. Hildebrandt MA, Lippman SM, Etzel CJ, Kim E, Lee JJ, Khuri FR et al. Genetic variants in the PI3K/PTEN/AKT/mTOR pathway predict head and neck cancer patient second primary tumor/recurrence risk and response to retinoid chemoprevention. Clin Cancer Res 2012; 18: 3705-3713.

291. Ichikawa W, Takahashi T, Suto K, Sasaki Y, Hirayama R. Orotate phosphoribosyltransferase gene polymorphism predicts toxicity in patients treated with bolus 5-fluorouracil regimen. Clin Cancer Res 2006; 12: 3928-3934.

292. Hood L, Heath JR, Phelps ME, Lin B. Systems biology and new technologies enable predictive and preventative medicine. Science 2004; 306: 640-643.

293. Han B, Gao G, Wu W, Gao Z, Zhao X, Li L et al. Association of ABCC2 polymorphisms with platinum-based chemotherapy response and severe toxicity in non-small cell lung cancer patients. Lung Cancer 2011; 72: 238-243.

294. Cheng J, Ha M, Wang Y, Sun J, Chen J, Wang Y et al. A C118T polymorphism of ERCC1 and response to cisplatin chemotherapy in patients with late-stage non-small cell lung cancer. J Cancer Res Clin Oncol 2012; 138: 231-238.

295. Yu D, Shi J, Sun T, Du X, Liu L, Zhang X et al. Pharmacogenetic role of ERCC1 genetic variants in treatment response of platinum-based chemotherapy among advanced nonsmall cell lung cancer patients. Tumour Biol 2012; 33: 877-884

296. Qian J, Gu S, Wu Q, Zhao X, Wu W, Gao Z et al. Association of CASP7 polymorphisms and survival of patients with non-small cell lung cancer with platinum-based chemotherapy treatment. Chest 2012; 142: 680-689.

297. Qian J, Qu HQ, Yang L, Yin M, Wang Q, Gu S et al. Association between CASP8 and CASP10 polymorphisms and toxicity outcomes with platinum-based chemotherapy in Chinese patients with non-small cell lung cancer. Oncologist 2012; 17: 1551-1561.
298. Liu D, O'Day SJ, Yang D, Boasberg P, Milford R, Kristedja T et al. Impact of gene polymorphisms on clinical outcome for stage IV melanoma patients treated with biochemotherapy: an exploratory study. Clin Cancer Res 2005; 11: 1237-1246.

299. Lin CH, Yeakley JM, McDaniel TK, Shen R. Medium- to high-throughput SNP genotyping using VeraCode microbeads. Methods Mol Biol 2009; 496: 129-142.

300. Paynter RA, Skibola DR, Skibola CF, Buffler PA, Wiemels JL, Smith MT. Accuracy of multiplexed Illumina platform-based single-nucleotide polymorphism genotyping compared between genomic and whole genome amplified DNA collected from multiple sources. Cancer Epidemiol Biomarkers Prev 2006; 15: 2533-2536.

301. Vacchelli E, Galluzzi L, Rousseau V, Rigoni A, Tesniere A, Delahaye N et al. Loss-offunction alleles of P2RX7 and TLR4 fail to affect the response to chemotherapy in nonsmall cell lung cancer. Oncoimmunology 2012; 1: 271-278.

302. Tan XL, Moyer AM, Fridley BL, Schaid DJ, Niu N, Batzler AJ et al. Genetic variation predicting cisplatin cytotoxicity associated with overall survival in lung cancer patients receiving platinum-based chemotherapy. Clin Cancer Res 2011; 17: 5801-5811.

303. Wheeler HE, Gorsic LK, Welsh M, Stark AL, Gamazon ER, Cox NJ et al. Genome-wide local ancestry approach identifies genes and variants associated with chemotherapeutic susceptibility in African Americans. PLoS One 2011; 6: e21920.

304. Wheeler HE, Gamazon ER, Stark AL, O'Donnell PH, Gorsic LK, Huang RS et al. Genome-wide meta-analysis identifies variants associated with platinating agent susceptibility across populations. Pharmacogenomics J 2013; 13: 35-43.

305. Li Y, Sun Z, Cunningham JM, Aubry MC, Wampfler JA, Croghan GA et al. Genetic variations in multiple drug action pathways and survival in advanced stage non-small cell lung cancer treated with chemotherapy. Clin Cancer Res 2011; 17: 3830-3840.

306. Wu X, Ye Y, Rosell R, Amos Cl, Stewart DJ, Hildebrandt MA et al. Genome-wide association study of survival in non-small cell lung cancer patients receiving platinumbased chemotherapy. J Natl Cancer Inst 2011; 103: 817-825.

307. Hu L, Wu C, Zhao X, Heist R, Su L, Zhao Y et al. Genome-wide association study of prognosis in advanced non-small cell lung cancer patients receiving platinum-based chemotherapy. Clin Cancer Res 2012; 18: 5507-5514.

308. Gatzemeier U, Pluzanska A, Szczesna A, Kaukel E, Roubec J, De Rosa F et al. Phase III study of erlotinib in combination with cisplatin and gemcitabine in advanced non-small-cell lung cancer: the Tarceva Lung Cancer Investigation Trial. J Clin Oncol 2007; 25 1545-1552.

309. Gatzemeier U, Groth G, Butts C, Van Zandwijk N, Shepherd F, Ardizzoni A et al. Randomized phase II trial of gemcitabine-cisplatin with or without trastuzumab in HER2-positive non-small-cell lung cancer. Ann Oncol 2004; 15: 19-27.

310. Kindler HL, Karrison TG, Gandara DR, Lu C, Krug LM, Stevenson JP et al. Multicenter, double-blind, placebo-controlled, randomized phase II trial of gemcitabine/cisplatin plus bevacizumab or placebo in patients with malignant mesothelioma. J Clin Oncol 2012; 30 2509-2515.

311. Fletcher JI, Haber M, Henderson MJ, Norris MD. ABC transporters in cancer: more than just drug efflux pumps. Nat Rev Cancer 2010; 10: 147-156.

312. Andjilani M, Droz JP, Benahmed M, Tabone E. Alpha6 integrin subunit mediates laminin enhancement of cisplatin-induced apoptosis in testicular tumor germ cells. Int $\mathrm{J}$ Cancer 2005; 117: 68-81.

313. Roodhart JM, Daenen LG, Stigter EC, Prins HJ, Gerrits J, Houthuiizen JM et al. Mesenchymal stem cells induce resistance to chemotherapy through the release of platinum-induced fatty acids. Cancer Cell 2011; 20: 370-383.

314. Kepp O, Menger L, Vacchelli E, Locher C, Adjemian S, Yamazaki T et al. Crosstalk between ER stress and immunogenic cell death. Cytokine Growth Factor Rev 2013; 24 311-318.

315. Kroemer G, Galluzzi L, Kepp O, Zitvogel L. Immunogenic cell death in cancer therapy. Annu Rev Immunol 2013; 31: 51-72.

316. Nakasone ES, Askautrud HA, Kees T, Park JH, Plaks V, Ewald AJ et al. Imaging tumorstroma interactions during chemotherapy reveals contributions of the microenvironment to resistance. Cancer Cell 2012; 21: 488-503.

317. Sasada S, Miyata Y, Tsutani Y, Tsuyama N, Masujima T, Hihara J et al. Metabolomic analysis of dynamic response and drug resistance of gastric cancer cells to 5 -fluorouracil. Oncol Rep 2013; 29: 925-931

318. Wang X, Yan SK, Dai WX, Liu XR, Zhang WD, Wang JJ. A metabonomic approach to chemosensitivity prediction of cisplatin plus 5 -fluorouracil in a human xenograft model of gastric cancer. Int J Cancer 2010; 127: 2841-2850.

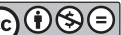

Cell Death and Disease is an open-access journal published by Nature Publishing Group. This work is licensed under a Creative Commons Attribution-NonCommercialNoDerivs 3.0 Unported License. To view a copy of this license, visit http://creativecommons.org/licenses/by-nc-nd/3.0/

\section{Supplementary Information accompanies this paper on Cell Death and Disease website (http://www.nature.com/cddis)}

